\title{
دور الوكلات السياحية في الترويج للسياحة
}

م م ريوار جال رشيد، قسم علوم السياحة، جامعة نوروز ، أقليم كوردستان العراق

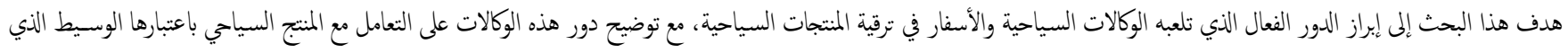

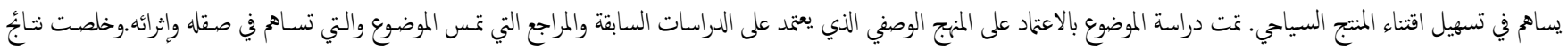

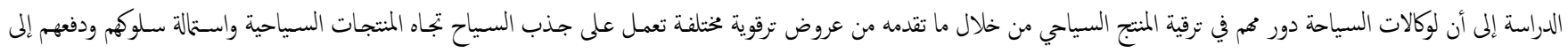

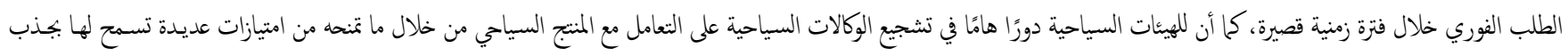

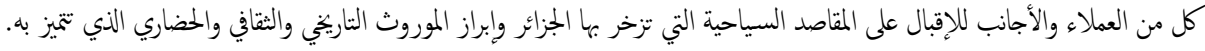
الكلمات الدالة: السياحة، الوكلات السياحية، ترويج السياحة، التنية السياحية، الخدمات السياحية.

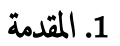

- - ما العمليات التنظمية التي تتبعها وكالات السياحة في الترويج للرحلات السياحية؟ - - هل تسام الوكلات السياحية في تطوير قطاع السياحة.

\section{1}

مهدف البحث الى تسليط الضوء على واقع ملموس للوكلات السياحية و الأسفار و دورها في تشجيع السياحة من خلال التعرف على درجة تنمية السياحة

$$
\text { التي تساهم بها وكالات السياحة . }
$$

3.1

تفتزض الدراسة ان للوكلات السياحية دور كير و هم في التزويج و التعريف بالاماكن و المراكز السياحية سواءكانت هذه المراكز و الهاككن السياحية دينة ام اثرية و تاريخية او كانت اماكن طبيعية ذات جالية خلابة كلاماكن الجبلية و

$$
\begin{aligned}
& \text { الينابيع و البحيرات و...الخ } \\
& 4.1
\end{aligned}
$$

يتبع البحث المنهج الوصفي و النظري في برهنة فرضية البحث و تحليل مشكلة البحث والوصول الى هدف الدراسة من خلال الاسلوب النظري و الادبيات الكثيرة التي تتناول اثر واهمية الترويج للارتقاء بالواقع السياحي. ومن خلال هذا البحث سوف نركز على دور الوكلات السياحية من حيث ترويهها للاماكن السياحية وتأثيرها على السائُ وماهي المساهات التي تقوم بها لتشجيع وتنمية
يكتل التسويق السياحي في الوقت الحاضر أهمية متزايدة، حيث يجتاج إلى ججهودات تسويقية متكمالة .ترنكز على متطلبات ورغبات العملاء طالبي الخدمات السياحية في الأسواق الخختلفة، ولقد وضعت أسس التسويق الحديث بحيث تخاطب الشرائ المتعددة من جمهور المستهلكين السياحيين.

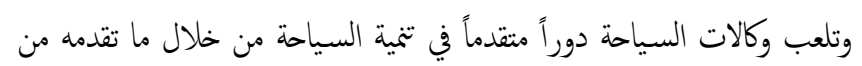
خدمات للسياح على أنواعهم. كما يناقش هذا البحث تطور مفهوم السياحة وإرتباطه بتغير مفهوم التنمية وتوجهاتها في المراحل الزمنية المختلفة بهدف الوصول الى أهم مرتكزات مفهوم التنمية السياحية، ودور الوكلات الساحية في الترويج للأنشطة السياحية وتطوريرها وتنميتها.

\section{1 مشكلة البحث}

تعتبر السياحة الداخلية و الخارجية هي النشاط السياحي الذي يتم من مواطني الدولة لمدنها الختلفة او من خارج الدولة التي يوجد بها جذب سياحي او معالم سياحية تستحق الزيارة و تنكون داخل حدود الدولة ولا تخرج عن حدودها، وتعمل السياحة بعفهوها العام على بعث النشاط في المناطق التي كانت عملة و استغلال طاقات البلد من مقومات، والى جانب المورد الطبيعي السياحي و المنشأة من فنادق و مراكز للاستجام. تتجلي مشكلة البحث من واقع تساؤل رئس: ما دور وكلات السياحية و الاسفار في تشجيع السياحة و التوويح لها ؟ و ينبثق من هذه السؤال تساؤلات

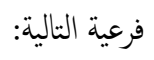




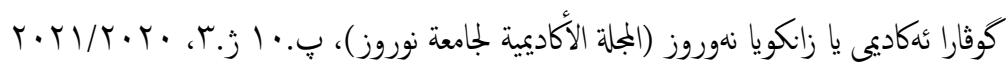

خدمات ومعلومات إستشارية وفنية ويعمل الترتيبات اللازمة براً أو بحراً أوجوا إلى أي مكان في العالم وكل هذه الخدمات والإستشارات تقدم إلى المواطنين مجانا بدون مقابل(عبدالله \& طاهر ، والشركات السياحية: Agencies Travel :هي الوسيط بين مالكي وموردي الخدمات السياحية الختلفة (الفنادق وأماكن الإقامة الأخرى - وسائل النقل المنشآتAgencies Travel) (Agencies Travel الشركات السياحية : ومستهلكي تاك الخدمات (السائين) (البطوطي، 2020، 49). وشركات السياحة ووكلات السفر - ومنظمو البرامج السياحية: هي الشركات السياحية الكبيرة والتي تتواجد بشكل أساسي في الدول المصدرة للسائين، وتقوم بعملية تجميع عناصر المنتج السياحي الخخلفة وتنظيمها في صوره برامج سياحيه متنوعه في توقيتات ومناطق محدده سلفاً وعمل الدعاية اللازمة لها وتسويقها وكذلك عمل كافه الترتيبات المتعلقة بتلك البرامج ،وتكون هذه الشركات من الكيانات الكبرى والتي تمتلك كل المقومات المالية والبشرية والفنية، ولها القدرة علي التعاقد مع موردي الخدمات السياحية، وتتحمل تكاليف الدعاية المختلفة للبرامج التي تعدها. ويتناك أو يسام منظمو الرحلات في معظم الأحيان بعض جوانب مكونات الرحلة فالعديد منها يمتلك طائرات ووسائل نقل مختلفة خاصه بها وكذلك فنادق وأماكن إقامه مختلفة أو منشئات سياحيه. وكيل منفذ المذدمات السياحية Agent Travel Ground هو المسئول عن تنفيذ البرامج السياحية المعدة مسبقاً بمعرفه منظمي الرحلات وحسب الإتفاق معها تواجد هذه الوكلات في المناطقوالبلدان المستقبلة للسائين ولادخل لها بترتيبات النقل الجوي بين دوله مصدر السائحين والمنطقة المستقبلة لمم. كما تقوم وكالات الخدمات السياحية بدور هام في تنشيط السياحة حيث تقوم بزياره نشاطها عن طريق توثيق علاقاتها مع منظمي الرحلات في الخارج. وتطور عمل هذه الوكالات السياحية حيث في مشاركه منظمي الرحلات في الخارج في تنظيم وتمويل وتحميل مخاطر إعداد برامج سياحيه إلي بلادها. وقام بعضها بنتح فروع لها في الخارج يكونوا علي إتصال دائم بنظمي الرحلات. كما قامت الوكلات السياحية الكبرى بإنشاء وكالات منظمه للرحلات بالإشتراك مع وكلات محليه في البلاد مصدر السائين تقوم بطرح برامج في السوق مباشره من خلال الوكلات الوسيطة - وكالة السفر والسياحة بالتجزئة Agent :
2. المبحث الاول: مفهوم الوكلات السياحية وتطورها

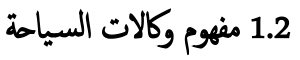

هي قسم من الأقسام المهمة في القطاع السياحي، ولها مسألة خاصة وعمليات متنوعة وشكل ميز للطبيعة العملية والإنتاجية فيها، وحسب الدراسات المعمولة حديثًا فإن أكثر من (50\%) من أوروبا الغربية والجزء الأكبر من الإنكليز والأمريكان واليابانيون من الذين يزورون دول أخرى يستخدموا خدمات

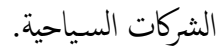
الشركة لغة: هي كلمة مشتقة من الأفعال شرك - جمع الشريك شركاء و(أشراك) مثل شريف وشرفاء وأشراف، و(شاركه) صار شريكه،

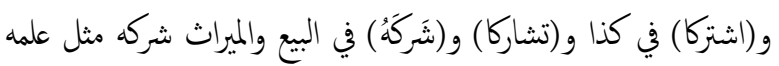
يعلمه (شَركَ)(الرازي، 1983، 336). الشركة اصطلاحًا: يعبر عن الشركة في الاصطلاح؛ فهي عبارة عن (مشروع تجاري اقتصادي يتكون من جانب مادي (رأس مال) وجانب إنساني (الخبرة والعمل) هيدفان إلى تكوين وحدة اقتصادية، وأورد في تعريف الثركة أيضًا بأهها (الشركة المؤلفة والمسجلة بمتضى قانون الشركات أو أي قانون ساري المفعول قبل نفاذه). تعريف الشركة: تعرف الشركة بأهه: "اتفاق شخصين أو أكثر على توحيد مساعيهم وأموالمم من أجل تحقيق ريح، كما يقصد بها (المؤسسة) أو (المنظمة) التي تتمخض عن هذا الاتفاق". وأما الشركة السياحية فهي: "الوسيط بين مالكي وموردي الخدمات السياحية الخختلفة (الفنادق وأماكن الإقامة الأخرى ووسائل النقل والمنشآت السياحية ومستهلكي تلك

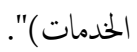

ويعني مفهوم شركات وكالات السفر والسياحة Agents Travel : أنها الجهة التي تساعد الناس على تنظيم الرحلات والعطلات عن طريق عمل تدابير إستعدادهم للسفر . وأيضاً هي شركات تنظم وتنتج وتيع للسكان المحليين وغير المحليين بضاعتها الجماعية الخاصة أو الرحلات السياحية الفردية وكذلك بيع الخدمات الإضافية المرتبطة بها أو تكون وسيلة عند بيع الرحلات السياحية من الخدمات والبضائع المنتجة من قبل شركة أخرى(البطوطي، كب، 2020، 36). وكذلك هي تلك الشركات التي احترفت تنظيم الرحلات السياحية الداخلية والخارجية لقاء أجر أو نسبة من الفنادق وشركات الطيران هي المكان الذي يقدم 


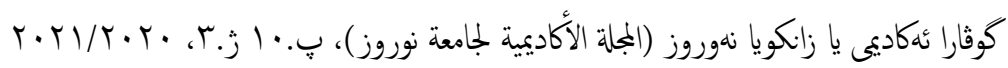

\section{2 أهية الوكلات السياحية}

تمارس الوكلات السياحية دورًا هامًا ومتميزًا في تطوير السياحة الخارجية والداخلية، كما أن لها أهمية بالنسبة للاقتصاد والآداب والعلاقات الاجتمعية وغيرها لدى أي دولة من الدول، كما تعمل هذه المكاتب على توظيف أيدي عاملة فتساهم بذلك في تحسين مستوى الدخل المالي للسكان ، وهي كذلك تؤثر على ميزان المدفوعات لكل دولة، وتساعد كذلك على تحسين الدخل القوي عن طريق الضرائب المتزتبة على أرباحما التي تجلهيا من العملة الصعبة. محليًا، تساهم هذه المكاتب في التسويق للبلد سياحيًا في الخارج والترويج للمناطق والمواقع الأثرية والثاريخية الهامة، من خلال عمل البرامج السياحية والرحلات المنظمة إلى المناطق السياحية ضمن بموعات سياحية في خختلف أنخاء العالم، وهي تعمل كذلك ضمن المفهوم التجاري الربحي في الخدمة السياحية، لهذا نجد أن الوكالة السياحية تعطي أهمية إلى عدد السياح القادمين، وتفضل تقديم الخدمة لجمموعات

سياحية).

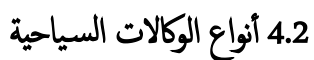

علينا أن نفرق بين ثلاثة أنماط لوكلات السفر قائمة في كثير من الدول التي

تطورت وتقدمت فيها صناعة السياحة ( فؤاد،2008، 69).

منظمو البرامج السياحية Tour Operators: وهي شركات سياحية كبيرة تتواجد بشكل أساسي في الدول المصدرة للسياح، وتعمل على تمميع عناصر المنتج السياحي المختلفة وتنظيها في صورة برامج سياحية متنوعة إلى مناطق محددة سلفًا ووفق توقيتات، فضلاً عن عمل الدعاية اللازمة لها وتسويقها، وكذلك عمل كافة التزتيبات المتعلقة بتلك البرامج. تمتلك هذه الشركات كل الإمكانيات والموارد المالية والبشرية والفنية، فضلاً عن قدرتها على التعاقد مع موردي الخدمات السياحية الخختلفة، وتتحمل هذه الشركات تكاليف التسويق لبرامجها السياحية، ويتناك العديد من تلك تك الشركات طائرات ووسائل نقل مختلفة، والفنادق وأماكن الإقامة المختلفة وغيرها من أنواع الخدمات السياحية. وكلات السفر والسياحة بالتجزئة: هذا النوع من الشركات يتواجد في الأسواق المصدرة للسياحة، وغالبًا ما يقتصر دورها على بيع البرامج

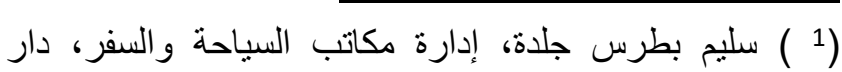

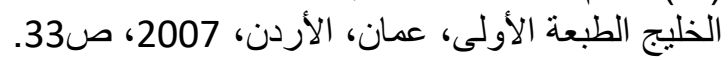

Travel Retail للسياحة ويقتصر دورها عاده علي بيع البرامج السياحية المعدة مسبقا بواسطه الشركات الكبرى من منظمي البرامج مقابل عموله معينه لها علي البيع يتم الإتفاق عليها أو ظظير مبلغا محددا علي الفرد أو حسب الإتفاق، يتمثل دور هذه الشركات في أنها وسيط بين منظمي البرامج السياحية أو موردي الخدمات السياحية والمستهاك السياحي (السائ)، ولايحتاج عمل هذه الشركات الي الخبرة الكبيرة في التخطيط أو التسويق الداخلي والخارجي والتي لابد من توافرها في الشركات الكبيرة من منظمي البرامج السياحية ، وهذه الشركات تعمد في عملها علي

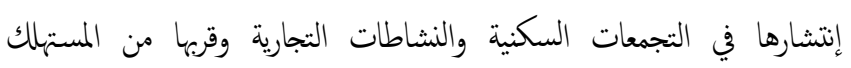
السياحي (العميل أو السائ) (الدباسين، 2007، 28). وكالات السفر وعلاقتها بشركات السياحة.

\section{2 نشأة الوكلات السياحية}

كان المسافر قديمًا يتولى خدمة نفسه بنفسه ويندبر أمور رحلنه، وبقي الأمر كذلك حتى العصر الروماني، حيث ظهر أثخاص تخصصوا في إرشاد المسافرين والعمل على مساعدتهم وتأمين حياتهم ومرافتته اثثناء الرحلة، ثم تطورت هذه العملية سنة 1841م بقيام توماس كوك بتنظيم الرحلات الجماعية في القطارات التي كانت آنذاك اختراعات حديثة، كما نظم رحلات برية كان يقوم بدور المرشد فيها، وبذلك تك يكون أول من أنشأ وكلة سياحة وسفر أسهاها "وكالة كوك وولده"، وقد ساعد التطور العلمي والتقني والاجتاعي آنذاك على تطور وازدهار وكالات السياحة والسفر ، حيث زاد الاهتمام بنشاطات وكالات السياحة والسفر على المستوى العالمي؛ فظهرت حركة عالية لتدعيم هذه الوكلات وتنظيها على المستوى العالمي، حيث تأسس سنة 1919م اتحاد تولى تمثيل رعاية مصاح هذه الوكالات وكان مقره بروكسل ثم أنشئ اتحاد منافس له في مدينة مونتريال، وفي سنة 1957، تم التوفيق بين الاتخادين في منظمة واحدة مقرها بروكل ضمت اتحاد وكالات السياحة والسفر لـ62 دولة وبذلك ظهرت منظمة الأوستا (جمعية وكلاء السياحة الأمريكية) ومنظمة الأوفتا (الاتحاد الدولي لمنظلات السياحة العالمية) وبمعية السياحة العالمية، وجميع هذه المنظات والجمعيات تهدف إلى العمل على حاية مصاح وكلات السياحة والسفر والحصول على تسهيلات سياحية وتوفير الظروف والأوضاع والضمانات اللازمة التي تضمن الحفاظ على ههنة السياحة

وتطويرها (سعيد،88،2004). 


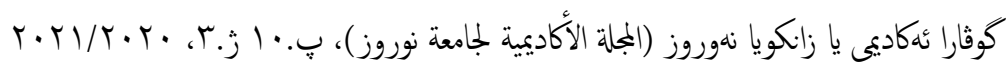

ب. وكيل السفر لا يتحمل أي خسارة في حالة فشل البرامج أو الرحلة السياحي إنما يخسر جزء من ثقة عملائه، أما شركات ووكلات السياحة حالة خسارتها أو فشل البرنامج فهي تخسر كثبر من الأموال التي تم إنفاقها على إعداد البرنامج وكذلك التسويق ودراسة السوق المستهدف والإعلان والدعاية. وكيل السفر إمكانياته المالية محدودة لا يستطيع القيام بأكثر من دور الوسيط أما شركات ووكلات السياحة فهي تكون ذات رؤوس أموال كثيرة يسمح لها بأن تقدم عدة أعمال كأن تكون موردة للخدمات ومستخدمة لها في نس الوقت (الزقرد،2008، 42).

\section{2 الهيكل التنظيمي للشركة السياحية}

يعدّ الهيكل التنظيمي لأي مؤسسة وسيلة أو أداة هادفة لمساعدتها على تحقيق أهدافها بكفاءة وفاعلية، من خلال المساعدة في تنفيذ الخطط واتخاذ القرارات وتحديد أدوار الأفراد وتحقيق الانسجام بين مختلف الوحدات والأنشطة، وتفادي التداخل والازدواجية والاختناقات وغيرها، من ناحية أخرى فين اللهيكل التنظيمي تأثيرًا كبيرًا على سلوك الأفراد والجماعات في المؤسسات، فتقسيم العمل والتخصص يتضمن إسناد محام وواجبات محددة للفرد، والالتزامات المتزتبة على الفرد وتوقعاته نتيجة لذلك قد توفر له الشعور بالرضا عن العمل. ويمثل الهيكل التنظيي صورة لهيكل المؤسسة، أو شكلا يوضح بالرسم كافة الوظائف الرئيسية والوحدات الإدارية والعلاقات التي تربط بين تلك الوحدات بعضها البعض، فضلاً عن بيان خطوط السلطة والمسؤولية التي تربط بين أجزاء المؤسسة والأبعاد الأفقية لنطاق الإثراف.

إن نجاح المنظمة يتمد في بناء هيكل تنظيي ناجح على قدرتها في العمل علي إيجاد بيئة عمل مناسبة وقدرتها على تحقيق درجة عالية من التكيف والتطابق والموائمة بين هيكلها التنظيمي وأهدافها، وكذلك كفاءة العنصر البشري، وكفاءة مواردها المادية، ويتبين من خلال ذلك أهمية وجود الهيكل التنظيمي للمؤسسة، من حيث مفهومه وتعريفه باعتباره الإطار الذي يحدد الإدارات والأقسام فن دون هيكل تنظيمي جيد ومناسب فين العمليات التنظمية تسير بشكل فوضوي لا يستند إلى لى أساس علمي متين حيث تتخبط المؤسسة وتنحرف عن مسارها وعن أهدافها فتصبح عديمة الفائدة وتتجه للانحدار والتراجع إضافة إلي هدر الموارد البشرية والمادية، فالهيكل التنظيمي غير الملائم يتزتب عليه أثار سلبية من حيث تدني
السياحية المعدة مسبقًا بواسطة الشركات الكبرى من منظمي البرامج مقابل عمولة معينة لها على البيع Commission on sales يتم الاتفاق عليها، أو نظير مبلغ معين على الفرد Per Person أو حسب الاتفاق، وتعمل هذه الشركات كوسيط بين منظمي البرامج السياحية أو موردي الخدمات السياحية والمستهلك السياحي (السائ)، وهي تتحمل تكاليف الدعاية ومستلزماتها الدعائية، ولا يقع عليها أي مسئولية مالية ناجمة عن تنفيذ البرنامج ولا تتحمل أي يخاطر، وتتمد هذه الوكلات في عملها على انتشارها في التجمعات السكنية والنشاطات التجارية وقربها من المستهلك السياحي (السائ). وكلات الخدمات السياحية: وهي الشركات التنفيذية التي تقوم بتنفيذ البرامج السياحية المعدة سلفًا من قبل منظمي البرامج السياحية في الأسواق المصدرة للسياحة، بمعنى العمل كوكلاء لمنظمي البرامج السياحية في المقصد السياحي. تتواجد هذه الشركات في البلاد المستقبلة للسياحة ولا دخل لها في ترتيب الطيران أو وسائل النقل الأخرى بين الدول المصدرة

$$
\text { للسياح والمستقبلة لم. }
$$

\section{2 العلاقة بين الوكلات و الشركات السياحية}

- التوزيع بالمملة :الدور الذي تقوم به وكلات السفر ينحصر أساسا في أنها تقوم بتسويق الخدمات والمنتجات التي تنتجها شركات السياحة لذلك فإن هذه الشركات السياحية تعتبر هي المنتج الذي يتولى إنتاج السلع .أما عملية التوزيع بالمملة الذي تمارسه وكالات ذات طابع قوي أو إقليم تؤهلها إمكنياتها

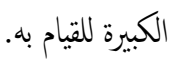

- - - التوزيع بالتجزئة: أما الأسلوب الآخر فهو عن طريق الوكالات المحلية التي تقوم بتوزيع المنتجات التي بين يدها بالتجزئة على عملائها فرداً أو مجموعة في حالة الرحلات السياحية(غوض الله،2013، 108. كما أن الفرق بين وكيل السفر وشركات ووكلات السفر والسياحة:أ. وكيل السفر بييع ما ينتجه مقابل عملة محددة مسبقا بينه وبين منتجي الخدمات فهو بمثابة وسيط فقط أما شركات ووكلات السياحة تقوم بإستثار أموالها في التوسع والقيام بتنظيم الرحلات والبرامج والتسويق والترويج وطبع الكتيبات والإعلان عن الرحلات. 


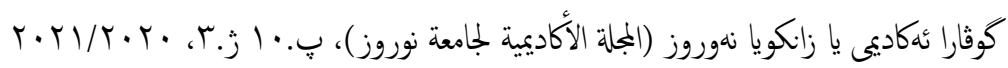

وتأسيسًا على ما سبق، نتعرف على شكل الهيكل التنظيمي للشركات السياحية، وأقساها وأنشطة كل قسم، ومعرفة العلاقة بين قسم السياحة وباقي أقسام الشركة، ويكننا بيان ما تقدم في الشكل رڤ (3) الآتي: رئيس مجلس الإدارة: غالبًا ما يتمثل بالمالك، أو مالكي الشركة سواء كنوا مستثمرين أو مساهمين، وغير ذلك من صور التملك والمشاركة في الملكية، ويقع عليه همام اتخاذ القرارات المتعلقة بالشركة السياحية بصفة عامة دون التدخل بالشئون الفنية داخل الثركة. المدير العام: هو القائم بالأنشطة داخل الشركة، ويعد المسئول عن بقية الأقسام، إذ يعد هزة الوصل بين أقسام الشركة المختلفة ورئيس مجلس الإدارة، فضلاً المسئول عن نجاح الشركة السياحية وتحتيق الأهداف المحددة من قبل مجلس إدارة الشركة السياحية. السكرتارية: تعد السكرتارية التنفيذية من أهم الوظائف الجوهرية في الحقل الإداري، فهو القسم الديناميكي الهام الذي يتولى كافة الأعال المساعدة، ويطلق لقب السكرتير على الشخص الذي يساعد مديره في العمل على أداء معظم أعماله، ويسجل له معلوماته، ويكتم أسراره، ويجب أن يكون القائم على هذه الوظيفة ملمًا جيدًا بأعمال السكرتارية وإدارة المكاتب، وتعد السكرتارية المسئول الأول عن تنفيذ العمل والتنسيق بين الإدارات المختلفة، والبريد الوارد والصادر والأرشيف وتحديد مواعيد المقابلات والاجتماعات، كل ذلك دون تضيع للوقت المستغرق والجهد المبذول في إتّام العمل، وتأتي أهمية وظيفة السكرتارية التنفيذية وإدارة المكاتب من واجبات الحفاظ على أسرار العمل سواء كانت هذه الأسرار خاصة بالعمل أو الموظفين، والإشراف على جميع الأعمال الإدارية، فضلاً عن تسهيل تدفق المعاملات، وإنجاز العمل في الوقت المطلوب.

O قسم السياحة: يعد هذا القسم القلب الناض للشركة السياحية، يشمل هذا القسم ثلاثة أقسام، هي: قسم السياحة الداخلية، وقسم

$$
\text { السياحة الخارجية، وقسم الحج والعمرة. }
$$

- - قسم السياحة الداخلية: يشمل البرامج السياحية التي يتم تنفيذها داخل البلد. معنويات وحافزية العاملين واتخاذ قرارات غير سلمة وتزايد النزاعات التنظمية والوظيفية والخفاض الطموح والإبداع وتزايد النققات، ولهذا فين عبء العمل والمس ؤولية التي تحملها الإدارة العليا في الوزارات والهيئات والمؤسسات وقد زاد زيادة ملحوظة في السنين الأخيرة. إن الهيكل التنظيمي عبارة عن (إطار يجدد الإدجارات والأقسام الداخلية الخخلفة للمؤسسة، فن خلال الهيكل التنظيمي تتحدد خطوط السلطة وانسيابها بين الوظائف، وكذلك ييين الوحدات الإدارية المختلفة التي تعمل معًا على تحتيق أهداف المؤسسة) (والي،5،2012). وتنبع أهمية الهيكل التنظيمي من خلال الآتي(اللوزي،2005): ترتيب العلاقات داخل المؤسسة. يعد إحدى الأدوات الإدارية التي تساعد التنظيم على الوصول إلى أهدافه حيث يشبه الهيكل التنظيم بالهيكل العظمي للإنسان كونه يمسك بالأنظمة الفرعية الختلفة لجسم الإنسان، فدون هذا البنيان تبقى الدوائر والأقسام المختلفة وحدات منعزلة عن بعضها. توضيح الإدارات والدوائر والأقسام والشعب داخل المؤسسة. توضيح المستويات الإدارية في المؤسسة واختصاصات ومسئوليات كل

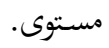
ولا يقف المفووم المعاصر اللهياكل التنظيمية عند حد اعتباره خريطة تنظيمة توضح التبعية الإدارية، والمسئولية الإشرافية أو مجرد تحديد منضبط للاختصاصات الوظيفية للوحدات الإدارية المكونة للتنظيم، وانما يمثل مع كل هذا أداة هدفها الهائي إلفاء القوى التي تعرقل أداء المنظلات وتحد من انطلاقها نخو غاياتها، ويعتمد نجاح الوزارات في بناء هيكاكها التنظيمية على قدرتها في خلق بيئة عمل مناسبة لتحقيق درجة عالية من التكيف والتطابق بين الهيكل التنظيم وأهداف المؤسسة وكذلك كفاءة العنصر البشر ومواردها (كامل،2005، 7). ويتغبّر ججم الهيكل التنظيمي لشركات السياحة وفقاً لمتغيرات عديدة؛ لعل من أهها جحم العمل داخل الشركة السياحية، فضلاً عن القدرة المالية للشركة، إذ إن انخفاض حجم العمل أو القدرة المالية للشركة يؤدي الى الخفاض دور التسويق السياحي، وفي حالة ارتفاع حجم العمل أو القدرة المالية للثركة يتعاظم دور التسويق السياحي، ومعنى ذلك أن حجم الهيكل التنظيمي للشركات السياحية يتغيّر لقسم التسويق والمبيعات ويجم العمل للشركة السياحية. 
قسم التسويق والمبيعات: يقوم بدراسة السوق السياحي الموجه إليه هذا البرنامج، وتحديد الشرائُ التسويقية المستهدفة وخصائصها، وتحديد الوسائل الدعائية والإعلانية المناسبة التي يكن من خلالها الوصول إلى أكبر عدد من الشرائح المستهدفة، ويقوم هذا القسم أيضًا بالاتصال مع الوكلاء المحليين والخارجيين وعرض الخدمات ونشاطات

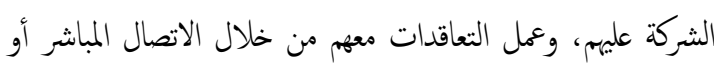
من خلال التواجد في المعارض السياحية المختلفة، كما ويقع على عاتق موظني هذا القسم همام الإعداد لإثراك الشركة في المؤترات والمعارض التي تعقد في العديد من دول العالم بشكل دوري سنويًا، إذ أن معظم الشركات السياحية وموردي الخدمات السياحية يقومون بالاشترالك في تلك المعارض وعرض منتجهم السياحي وبرامجهم، ويجدوا في ذلك فرصة للالتقاء بالشركات الأخرى وعمل

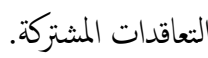

قسم حجز وإصدار التذاكر (قسم الطيران): يقوم هذا القسم بهام حجز وإصدار النذاكز، وغالبًا ما يكون منفصلاً عن الشركة بكان خاص به، ويرجع السبب في ذلك إلى أعمال القسم التي توجه إلى الجمهور بصفة عامة، ويتطلب هذا القسم أن تكون الشركة السياحية متعاقدة مع "أياتا IATA"، وحاصل على رق وكيل (IATA Agent) ليتمن من إصدار تذاكر الطيران، ويقوم المسئول عن الحجز بالمهات الآتية: - - استقبال ججوزات تذاكر الطيران سواءكان من خلال التليفون

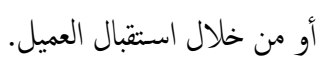

- - عمل حجز تذاكر الطيران للعملاء وإصدار تذاكر للعملاء

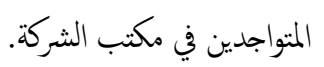

- - عند الحجز عن طريق التليفون، يتم الحجز المبدئ وإعطاء العميل معلومات الحجز الخاصة به على أن يراجع مكتب كنب

$$
\text { الشركة لإصدار النذاكر في وقت معين يجدده له. }
$$

- متابعة الحجوزات المختلفة وتأكيد الحجوزات للعملاء، وعلى

$$
\text { الخصوص الذين لم تصدر لمم النذاكر بعد. }
$$

- - قسم السياحة الخارجية: يشمل البرامج السياحية التي يتم تنفيذها خارج البلد من مواطني البلد، وكذلك البرامج السياحية التي تنفذ داخل البلد للسائين الدوليين. - قسم الحج والعمرة: يشمل إعداد البرامج الخاصة بشعائر ومناسك الحج والعمرة. وغالبًا ما يندرج تحت هذا القسم أقسام البرامج السياحية والتسويق والحجز ويجز النذاكر والتشغيل، ووفق ما يآتي (البطوطي، 2020): - - قسم الحجز: وهذا القسم مسئولاً عن استقبال كافة الحجوزات الخاصة بالشركة والتعامل معها، وكذلك عمل الحجوزات المختلفة التي تتص البرامج التي تنفذها الشركة والمعدة بواسطة معد البرامج السياحية سواء الخاصة بالفنادق بأنواعها أو وسائل النقل الخخلفة أو المطاعم ... إحلح. المسئول عن استقبال وتوديع السائين أو المجموعات السياحية، وعمل كافة إجراءات الوصول والسفر لم، وكذلك مرافتهم إلى الفنادق التي سوف يقيمون بها، وعمل إجراءات تسكينه، وكذلك إجراءات مغادراتهم وتسهيل كافة الإجراءات

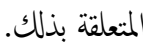
- التور ليدر Tour Leader: هو الشخص الذي يرافق المجموعة السياحية طول الرحلة، وهو الذي يقوم بعمل كافة الترتيبات الخاصة بهم منذ وصولم وحتى السفر ، وكذلك تزويد السياح بكافة المعلومات المتعلقة بالرحلة وتوضيحها لمم، فضلاً عن الإجابة عن كافة تساؤلاتهم واستفساراتهم ومساعدتهم في حل أي مشكلة قد تعزضهم أثناء الرحلة بععنى أن هذا الشخص يعدّ المسؤول الأول عن المجموعة خلال مدة الرحلة أمام الشركة، وهزة الوصل بين المجموعة السياحية والشركة، فضلاً عن قيامه بعملية الارشاد السياحي أي يكون مرشداً سياحياً .Guide 


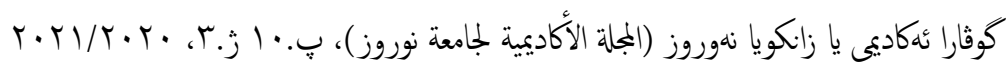

يكتوي كل منها على 25 أو 50 قسيمة، وتختلف مقاسات وأشكال قسيمة التبادل من مكنب إلى آخر ولكنها جميعًا يجب

أن تتضمن خانات تملأ بالبيانات التالية عند استععالها:

- - اسم المسافر من وقع على سفره، إذ أن القسيمة شخصية ولا يجيوز تخويلها.

- - اسم المدينة التي تبدأ منها الرحاة والمدن التي تمر بها.

$$
\text { - - م اسم المدينة التي تنتهي بها الرحلة. }
$$

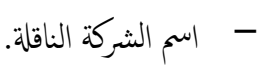

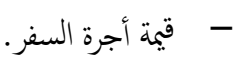

- تاريخ بدء الرحلة وتاريخ بدء كل مرحلة من مراحلها وتاريخ انتهائها. - - م الفنادق التي سيقيم فيها أثناء رحلته.

- - - تحديد عدد الليالي والأيام التي سيقضيها السائح في البلد. - - الإثشارة إلى الخدمات الإضافية إن وجدت.

قسم شئون الموظفين والتدريب: هو من الأقسام الهامة والحيوية في الشركات السياحية على العموم، كونه المسئول عن تلبية احتياجات الشركة السياحية من العالة المدربة من ذوي الحبرة في مختلف الأقسام، وغالبًا ما يتم الإعلان عن حاجة الشركة للموظفين واستقبال طلبات التعيين وفصها وعمل المقابلات والاختبارات مع المتقدمين في حضور مسئول القسم لاختيار العناصر المتيزة، كما ويقوم القسم بالتنسيق بخصوص تدريب العاملين بالشركة سواء العاملين الجدد على الأعال التي سوف يقومون بها وتكييفهم على نظام العمل بالشركة وكيفية الاتصال، وكذلك عمل البرامج التدريبية الدورية والدورات التنشيطية للعاملين القدامى وتنمية قدراتهم في الأقسام المختلفة، ويقوم هذالقسم أيضًا بجفظ ملفات العاملين ومرتباته وإجازاتهم وجميع الأمور المتعلقة بككاتب العمل والتأمينات الاجتماعية وبحات التنتيش المختلفة.
- - تحديد أفضل خطوط السير لرحلات العملاء، وكذلك أفضل

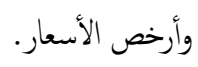

- - متابعة العملاء من خلال الاتصال بهم لاطلاعهم على حالات

$$
\text { الحجوزات الخاصة بهم في حالة عدم تأكيد الحجوزات. }
$$

- - محاولة إيماد حلول للمشاكل التي قد تنشأ عند حجز التذاكر، مثل: عدم توافر مقاعد على رحلة معينة، تغير مواعيد حجز بعض الرحلات، إلغاء الرحلات من قبل شركات الطيران، محاولة تحقيق الحذمات الإضافية التي قد يطلبها العميل، وتقديم أفضل خدمة مككنة للعملاء لضمان استمرار هر وبقأهم كملاء. O مسم النقل: يؤمن هذا القسم النقل السياحي ووسائل النقل عند تنفيذ البرامج السياحية، سواء وسائل النقل المملوكة للشركة السياحية أو عن طريق الإيجار الخارجي عن الشركات السياحية أو

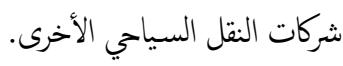
O مسم الشئون المالية: هو من الأقسام الهامة في الشركة السياحية، ويعني بكافة الشئون المالية المتعلقة بالشركة من خلال دورة محاسبية متكمالة كلك من الايرادات والمصروفات الخاصة بالشركة، فينقسم بذلك عمل القسم إلى: حسابات الإيرادات، حسابات المصروفات، حسابات المرتبات، الإحصاءات والموازنات، تجري المعاملات بين جميع مكانب السفر وبين جميع الشركات الناقلة بموجب قسيمة التبادل والاسم الأكثر انتشارًا (Voucher)، وتستخدم هذه القسيمة لإخراج تذكة السفر على جميع الشركات الناقلة دون استثناء، سواء كانت شركات طيران أو ملاحة أو سكك حديدية بالخارج، كما لمان تستخدم القسيمة ذاتها بالنسبة للإقامة بالفنادق.

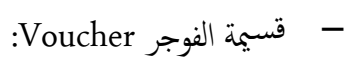
تعد قسيمة التبادل وثيقة ذات قيمة مادية مثل الشيكات، ترص مكاتب السفر على وضع نظام داخلي محكم بالنسبة لطريقة تداولها وأحكام الرقابة علها منعًا لسوء استخدامحا، وتطبع قسيمة التبادل بثلاثة أو أربعة نسخ (حسب مقتضيات النظام الداخلي في مكاتب السفر) ثم تجمع في دفاتر الشيكات 


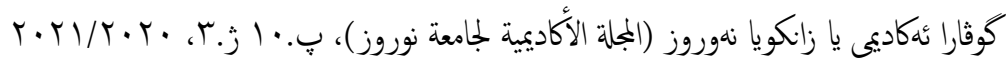

أ. الاتصال: وهي عملية التواصل مع الزبائن الحمتلين لمعرفة ميولم

ورغباتهم لخلق منتج سياحي متناسب مع هذه الرغبات، وهذا باتباع عدة وسائل مختلفة. ب. التنمية: هي عملية التطوير المستمر للمنتج حتى وإن كان مقبولا من طرف الزبون وذلك لضان عودة السائح مرة أخرى واستهلاكه لهذا المنتج، الذي في كل مرة يجده أحسن من المرة السابقة وليس العكس، وذلك عن طريق تخطيط وتنمية المتاحات الجديدة. المراقبة: تمكننا من الاستعال الفعال للإمكانيات السياحية المتاحة، فن خلال المراقبة والمنابعة لعملية استهلاك المنتج السياحي تستطيع المنشآة السياحية معرفة عيوب المنتج واصلاحما من خلال عملية النغذية العكسية.

المزيج التسويقي السياحي: هو ذلك التفاعل الذي يتم بين عدد من النشاطات المتغيرة التي تؤثز على قرار المستهلك وهو يتكون من: أ. المنتج (الخدمة السياحية):هو التجربة التي يعيشها الزائر منذ لحظة مغادرته مكان إقامته الأصلي حتى عودته إليه، وتعتبر إستراتيجية المنتج من أكثر عناصر إستراتيجية التسويق أهمية حيث تدور الاستراتيجيات التسويقية بشكل رئسي حول المنتج بدونه لا يكون هنالك أسعار أو ترويج أو قنوات توزيع. لهذا يكن القول أن المنتج السياحي هو أساس استراتيجية التسوبق السياحي .وأن المنتج السياحي ليس مقعدا في طائرة أو في غرفة نوم في فندق أو استرخاء

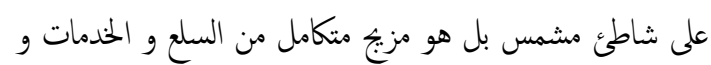
أهم عناصر المنتج السياحي(كوتلر،2009):

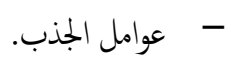
- - م- الشعور بالرضا بما يتحقق من منفعة وإشباع. - - مهولة الوصول للبلد. ب. التسعير السياحي: يعبر عن كافة مصاريف الانتاج السياحي من تكاليف الاطعام، النقل والإيواء، وغيرها من الخدمات السياحية المرافقة، فهو يمثل العنصر المتغير في المزيج التسويتي السياحي، ذلك تونك أنه يكن تخطيطه وهيكله بمرونة معقولة، ويعرف سعر المنتج

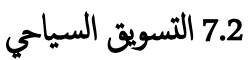
التسويق السياحي عبارة عن عملية دورية تبدأ بهم دوافع وحاجات ورغبات ومطالب المستهلكين السياحيين (السائحين)، والذين يتم إنباع رغباتهم بتقديم البرامج السياحية والعروض المناسبة، من خلال دخولم في عملية تبادل مع القائمين عن التسويق. تعريف التسويق السياحي: يعرف التسويق السياحي على أنه: "التنفيذ المنظم والمنسق للسياسات السياحية، من خلال المؤسسات الحكومية والخاصة على المستوى المحلي، الإقليم والدولي لتحقيق الإشباع لدى الأسواق المستهدفة، والحصول على عائد مناسب، سواء كان تقديم خدمة، نو سياحي، دخل سياحي.."(مقاباة، 2001). كما أن التسويق السياحي هو: "عبارة عن عملية إدارية تقوم بها المنظلات السياحية و المشاريع السياحية من خلالها بتحديد بمحوعتها السياحية الفعلية و المتوقع الاتصال بهم لغرض التحفيز وإشباع رغباتهم و دوافعهم و تبني المنتوج السياحي المطلوب من قبلهم، ذلك لغرض تحقيق الإشباع الأكبر للسائُ و تحتيق أهداف التنمية السياحية"(مقابلة، 2007). كما عرف بأنه: "عملية موجهة نحو السائين تهدف إلى تأمين وتلبية احتياجاتهم الاستهلاكية، وذلك عبر القنوات التوزيعية للمؤسسات السياحية المختلفة، والتي تثفاعل مع هؤلاء السائين تحت ضغط وقيود البيئة الخارجية التي تنشط في هذه المؤسسات السياحية"(هدير،2010). وبصفة عامة يكن تعريف التسويق السياحي بأنه: نشاط إداري وفني تقوم به المنشآت السياحية بهدف دخول أسواق جديدة، وكسب زبائن جدد والحفاظ عليهم وتحتيق التوافق بين المنتج السياحي ودوافع السياح. وظائف التسويق السياحي: من التعاريف السابقة للتسويق السياحي يتضح أن النشاط التسويتي في مجال السياحة تمتد آثاره إلى المراحل التالية لمرحلة بيع المنتج السياحي، ولا تقتصر على مجرد دراسة الأسواق السياحية والمنافسين وفهم طبيعة واحتياجات السياح والثأثير في قراراته الشرائية، بل يتعدى ذلك إلى مضاعفة الجهود التسويقية المبذولة وتحديث المعلومات عن السوق السياحية وما يحدث فيها من ظواهر مختلفة والتي تطرقت لها المنظمة العالمية للسياحة تحت مسمى وظائف التسويق

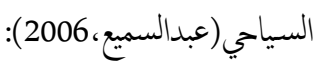




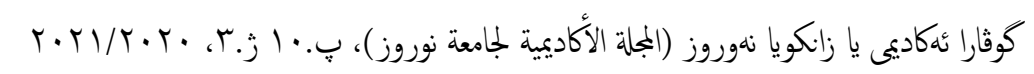

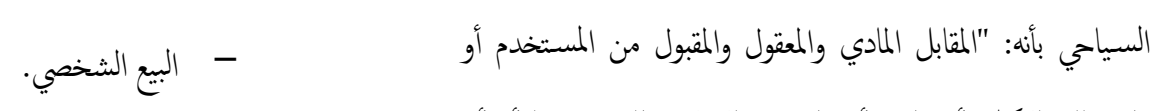

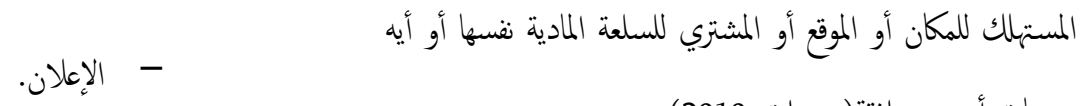

$$
\begin{aligned}
& \text { خدمات أخرى مرافقة(عبيدات،2010). }
\end{aligned}
$$

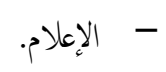

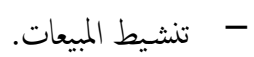

3. المبحث الثاني: دور وكلات السياحة والسفر في القطاع السياحي

$$
\text { الأعال التي تقوم بها شركات ووكلات السفر }
$$

تقديم المعلومات والإستشارات إلى العملاء عن الرحلات المناسبة وأسعارها

$$
\text { والأماكن المناسبة لمم حسب رغباته. }
$$

حجز وبيع تذاكر السفر الخاصة بوسائل النقل المختلفة برية وبحرية وجوية. تنظيم وتنفيذ الرحلات السياحية الجماعية والفردية في الداخل والخارج

$$
\text { وعمل الترتبات اللازمة لها تزويد العملاء بالمطبوعات. }
$$

وعمل الترتبات اللازمة نخو ججز الغرف بالفنادق وأماكن الإقامة المختلفة. الإمام التام بكافة المعلومات الخاصة بجداول ومواعيد رحلات الطائرات

$$
\text { والقطارات وأسعار الخدمات المقدم بها. }
$$

عمل الترتيبات اللازمة الخاصة بحجز الغرف بالفنادق وأماكن الإقامة الختلفة.

$$
\text { تنظيم الإنشتراك في الأحداث السياحية الخاصة والمهرجانات الخختلفة. }
$$

مساعده العملاء في تجهيز المستندات الخاصة بالسفر واستخراج التأشيرات

السياحية.

$$
\text { تنظيم وتحديد أماكن الزيارة التي يتضمنها البرنامج السياحي . }
$$

إجراء كافه الترتبات الخاصة برحلات الجمموعات ذات الإهتمات

الخاصة(البطوطي،

$$
\begin{array}{r}
1.3 \\
\text { إجراءات شركة و وكالة للسفر } 1.1 .3 \\
\text { الإجراءات }
\end{array}
$$

الحصول على تزخيص بإقامة وكالة للسفر والسياحة و يتطلب القيام بسلسلة من الإجراءات وتوفير عدد من المتطلبات قبل الحصول على التزخيص اللازم ـ وتوجد

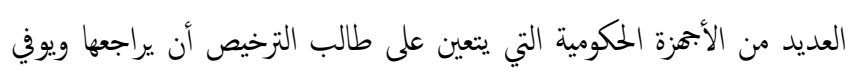

سياحية وينظر السائُ إلى السعر بمقدار ما يعود عليه من مزايا

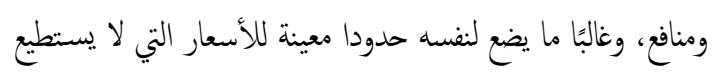
تحملها ودفع مقابل حصوله على المنتج السياحي الذي يجهل الكثير عنه(Anthony,1997) ) ، وهنا يكن للتسويق السياحي الإلكتروني أن يلعب دورًا محمًا في إعطاء نظرة شاملة عن المنتج السياحي وتبرير سعره، وكأن السائ يقوم بتجربة سياحية متصرة تساعده على اتخاذ قراره الشرائي. ج. التوزيع السياحي:يعمد التوزيع السياحي على قناتين، ها: طريقة التوزيع المباشر، وفي هذه الطريقة تقوم الشركات السياحية بالاتصال بالسياح بشكل مباشر من خلال فروعها و مندوييها أو عن طريق شبكة الاتنزن، من أجل إقناعم بالتعاقد على برامج الشركة السياحية، وطريقة التوزيع غير المباشر وفي هذه الطريقة تعتمد

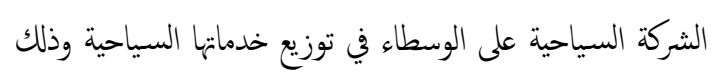
نظرا لاتساع السوق السياحي و الانتشار الجغرافي الكبير للعملاء، ويككن أن يلعب التسويق السياحي الاكتروني دور الوسيط خاصة عند بعد العملاء عن المركز الرئسي للشركة و فروعها.

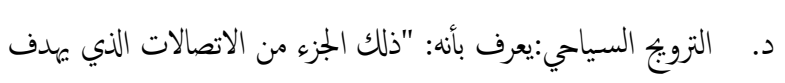

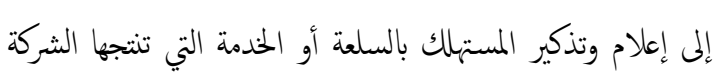

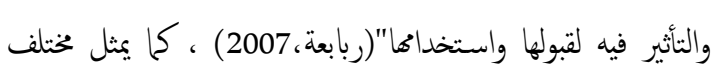
الجهود الترويية المبذولة عن طريق مختلف وسائل الاتصال بغية توضيح الصورة السياحية للبلد، وهو يعبر عن تنسيق بين الوزارة

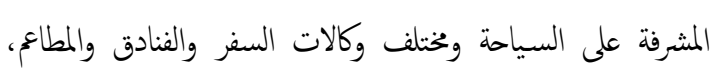
خطوط الطيران المتواجدة والجهات الأخرى المشرفة على النقل والأمن الداخلي وغيرها، ويتكون المزيج الترويجي من أربعة عناصر بمتطلباتها:- 


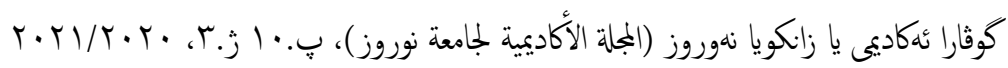

شركات الخطوط الجوية المحلية والعالمية ووكلاء السفر في المدينة المعنية ..الح · ودراسة العلاقات مع شركات النقل السياحية والفنادق والموتيلات والمخيات وكذلك دراسة ميدانية عن مدى توجه المواطنين إلى وكلاء السفر ومدى ثقته

بناك الوكلات (Chudhary, 2010 (56).

2.3 الهيكل التنظيمي للشركات السياحية

يختلف حجم الهيكل التنظيمي من شركة إلى أخرى بناء على ،حجم نشاط الشركة

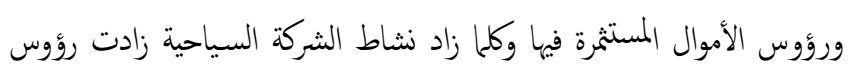
الأموال وزاد حجم الهيكل التنظيمي فهيا فبالتالي زاد عدد العاملين والموظفين بها وتعددت المستويات الوظيفية .وأيضا يختلف حسب حجم السوق السياحي التي تتعامل معه الشركة السياحية وكلما زاد ججم السوق زادت الحاجة إلى التوسع في الهيكل التنظيمي.

- - رئيس مجلس الإدارة: هو الشخص الذي يمثل عادة مالك أو مالكي الشركة سواء كانوا مستثمرين أو مساهمين، ويقوم بإتخاذ القرارات المتعلقة بالشركة السياحية بصفة عامة دون الثدخل بالشئون الفنية داخل الثركة.

- المدير العام: هو الشخص الذي يقوم بإدارة النشاط داخل الشركة السياحية ويمثل هزة الوصل بين أقسام الشركة الختلفة ورئيس مجلس لئس الإدارة وهو المسئول عن نجاح الشركة السياحية وتحتقها الأهداف المحددة

من قبل إدارة الشركة السياحية عبدالله\&الطاهر، 2013، 58. العوامل التي تحدد نوع الوكالة ومستوى أدائها, توجد العديد من العوامل تتفاعل في ما بينها لتحدد طبيعة وحجم النشاط الذي تمارسه وكالات السفر بإعتبارها مؤسسات إستثمارية تهدف إلى الربح بصوره مباشره بقدر ما تهدف إلى الإسهام في النشاط الإقتصادي لأسباب إقتصادية وإجتاعية معروفة .ومنها عوامل طبيعية خارجية تتعلق بالمجتع ككل لا دخل للوكالات ولا سيطرة عليها ، وعوامل ذاتيه

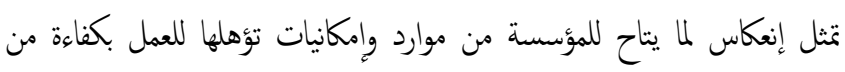
خلال سيطرتها الإدارية والتسويقية ونجاحما في العمليات والأنشطة التي تمارسها

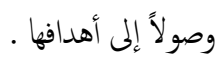

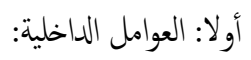

O موقع الوكالة: موقع الوكلة المناسب يمثل الخطوة الأولي وإذا تحقق كان ذلك أحد أهم ضهانات نجاحما ، ويمثل أحد مقومات جذب العملاء .

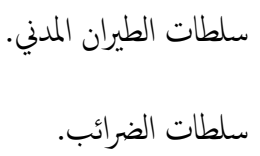

فسلطات الطيران المدني لها أن تطمئن على توفر كافة الشروط التي تؤهل طالب الترخيص للدخول في هذا المجال وخاصة فيا يتعلق بتوفير عناصر السلامة في أداء الوكالة المزمع إنثاؤها. وأما سلطات الضرائب فهي معنية في الأساس بأداء طالب الترخيص لالتزاماته تجاه الدولة حتى يمق له الخصول على الترخيص.

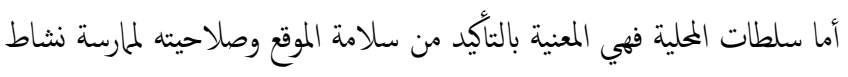
متعلق بتسويق الخدمات السياحية.

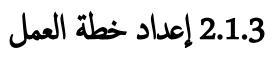
وهي وثيقة تصف النواحي المتعلقة بتأسيس وإدارة وتشغيل الوكالة المزمع إقاتها لذلك يتعين على واضع الخطط أن يجعلها تشتمل على النواحي المالية ، والتسويق ،وإستراتيجية العمل الإداري

3.1.3 الإنضام إلى الإياتا

هي اختصار لإسم الاتحاد الدولي لشركات الطيران وهي الجهة التي أصبحت تنظم العلاقات بين شركات الطيران ووكلات السفر والسياحة على مستوي العالم، كما توجد وكلات السفر غير الأعضاء في الإياتا : توجد العديد من الوكلات ظلت تباشر نشاطها دون أن تصبح عضواً في أي من الإتحادات الإقليمة أو لو لون

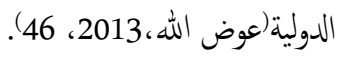

4.1.3 دراسة السوق

تتطلب دراسة السوق الحصول على البيانات من قبل الجهات الحكومية مثل وزارة السياحة والتخطيط وكذلك الإحصائيات والبيانات المتعلقة بالحركة السياحية وجنسيات السائهين والمجموعات السياحية ودراسة نسب الإنغال في الفنادق ومقارنتها مع السنوات السابقة، وأيضا حركة الطيران المدني والمؤسسات التسويقية في البلد والشركات السياحية.

5.1.3 دراسة المنافسين

دراسة عدد وكالات السفر الموجودة في البلد وخصوصا في المدينة التي يود إنشاء الشركة السياحية بها، ومواقعها ومدي مستوي التعاون بينها وبين الشركات السياحية الأخرى وشركات الخدمات المساندة لها ودراسة مجال التعاون بين 


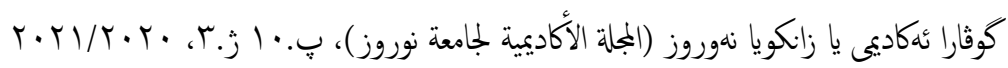

- - يتواجد مكتب الشركة في مناطق نكثر بها حركة المشاة، على الشارع الرئيسي أو داخل مركز تجاري، ويكون واسعًا لاستيعاب الموظفين والأجزة، وتوفر المكان المناسب لخدمة الزبائن

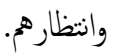
- - - يتأثز موقع المكتب بشريحة سكان المنطقة، فلا يككن بيع الخدمات لرحهاة سياحية بأسعار مرتفعة النكليف في حي متواضع. - - تكون لمكتب الشركة السياحية نافذة عرض فيها أدوات عرض مختلفة مثل الملصقات والصور والثاثيل وخلافه، وأما مكاتب الطيران فغالبًا ما تعرض نموذجًا أو صورًا للطائرات الحديثة التي تسيرها شركة الطيران. كما وأنه قد يتم عرض صور مكبرة لمقعد

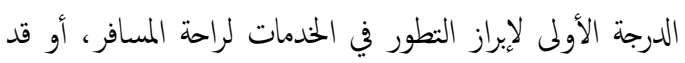
يعرض المكتب في نافذة العرض صورًا لمضيفات ومضيفين مبتسمين يشرفو على راحة المسافرين، وإبراز الأسعار وأي تخفيضات ممنوحة في مكان بارز من نافذة العرض، وتخرص المكلتب على تغيير ديكورات نافذة العرض بين فترة وأخرى، فهي تغير العرض كل (4-6) أسابيع، ويتم التزكيز في كل مرة على نقطة بيعية جديدة، مثل منطقة الإجازة ووسائل الجذب بها صورًا

$$
\text { لوسائل الانتقال وغيرها من الصور السياحية. }
$$

- - يجب توفر البساطة والراحة وسهولة تحرك العملاء في تصميم مكتب الثركة من الداخل، وإن حسن تنظيم المكتب يعكس تفهم إدارته للتطوير والتحديث، مع الأخذ بنظر الاعتبار الألوان والأثاث والملصقات؛ إذ تعكس روح المكتب وواجحة يطل منها المتزددون على المكتب وعلى المنشآة. - - وضع لوحة خارجية عليها الاسم التجاري للمرخص لها -أي الشركة- باللغة العربية والإنجليزية، بخط كبير وواضح. - - تتوفر في المكتب الحد الأدنى من الأجزة/ وسائل الاتصالات (هاتف - فاكس - الاتصال عن طريق الإنترنت، ... إلخ)، فضلاً عن وسائل الأمن والسلامة، وكذلك توفر متطلبات الراحة والتهوية والنظافة، والخدمة المناسبة للعملاء.
O حسن إختيار العاملين فيها : من أهم مقومات النجاح في ميدان السياحة إختيار العنصر البشري المؤهل وذا الخبرة، ومن أهم أسس نجاح الشركات السياحية امتلاكها الموارد البشرية المدربة والمؤهلة ل لعمل في القطاع السياحي الذي يتيز عمله بالاعتاد على العنصر البشري، فإن الموارد البشرية العالية القدرة، والماهرة في الأداء النكنولوجي، فضلاً عن تتعها بالحبرة في الإدارة والديناميكية تعطي الدفعة القوية للنفاذ في الأسواق ، لذلك تحتاج الموارد البشرية إلى تنمية قدراتها والتزكيز على تدريب العاملين من أجل رفع الكفاءة النكنولوجية والإدارة والتسويق، والاهتمام بالتعليم والتدريب المستمر للخرييين في مجالات التكنولوجي المتقدمة(حنفي،2008). O كفاية عنصر التمويل: يمثل عصب أي نشاط إقتصادي سواء في مؤسسات الإنتاج أو مؤسسات الخدمات و كفاية عنصر التمويل لدى وكالات السفر يمل علامة ميزة في وجودها حيث يضمن لأي وكالة القدرة على الإستمرار في كسب الشركات. O كفاية عنصر التجهيز : يقصد بالتجهيز توفر الوسائل والمعدات في المستوى الذي يؤهل الوكالة للعمل بكفاءة ويؤهلها لمواكبة أي تطور

$$
\text { يحدث سواء في المعدات والأجزة . }
$$

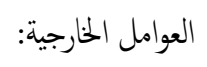

O الوضع الإقتصادي: يتمثل في توفر المصادر الأساسية التي تزود

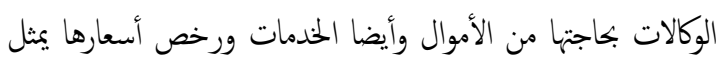
أحد أهم العوامل الإقتصادية التي تساعد المستثمرين على إنشاء وإدارة

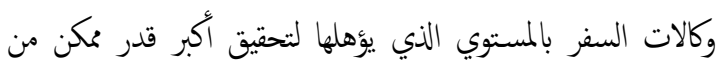
النشاط وجني أكبر حصيلة من الأرباح. الوضع الديموغرافي: يقصد به الخصائص والسمات التي تميز سكان البجتع وتوثر على سلوكهم كسائحين أو مسافرين، فالوضع الإجتاعي هو الذي يمثل مدى إقباله على السفر ويحدد ما إن كان يظل مسافراً كفرد أو جاعات (أسرة مثلا). O عوامل النجاح للشركة السياحية، ويتفرع الموقع إلى عوامل تساهم في

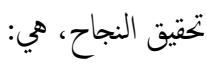




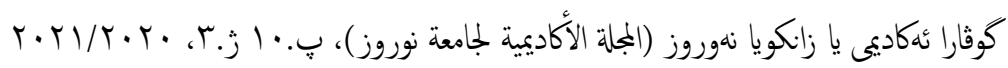

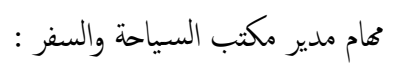

التخطيط : يعتبر المدير المسئول الرئيسي لكافة أنواع الخطط .فقد توجد خطط يومية وأسبوعية أو شهرية أو حتى سنوية تساعد مكتب السفر في تحقيق أهدافه. فن واجب المدير وضع الخطط المناسبة لعقد الإجتاعات اللازمة مع الموظفين والعاملين في المؤسسة أو مع العملاء والمرشدين السياحيين من أجل مناقشه أهداف المكتب وجمع المعلومات اللازمة للقيام

$$
\text { بالمهام بشكل أفضل يضمن نجاح المؤسسة . }
$$

الرقابة:على المدير مراقبة أعمال المؤسسة كلإعال المحاسبية وإدارتها ووعليه

$$
\text { مراقبة عملية التسويق في مكتب السياحة والسفر. }
$$

التنظيم: المدراء هم المسؤلون عن عملية التنظيم الداخلي لمكتب السياحة والسفر والتي تشتمل معرفة نوعية الوظائف المطلوبة والعدد المطلوب من الكوادر الختلفة. فقد يكون له الحق المطلق في توظيف العدد المطلوب من

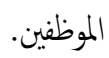

التوجيه: على المدير توجيه الموظفين من خلال وسائل مختلفة مثل تحفيز العال والعمل بشكل جاعي وحل المشاكل العالقة والتواصل الفعال داخل المؤسسة وتدريب الموظفين على الأساليب الحديثة في تنفيذ الأعمال. التوظيف: تعتبر همة التوظيف من مهام المدير، وعليه إختيار الموظف المناسب وتوظيفه ووضعه في المكان المناسب وتدرييه وتطويره من أجل النهوض بالمؤسسة والوصول إلى الأهداف التي وضعت عند نشأتها . الإتصال: وهو عبارة عن عملية تبادل للآراء والأفكار بين كافة المستويات العاملة ، وهو سر نجاح أو فشل المكتب، فالمدراء بحاجه لتطوير مهارات الإتصال فيا بينه وبين العاملين من جحة وببنه وبين الزبائن من جهة

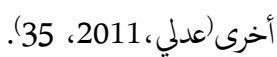
إختيار الكادر المناسب لمكتب السياحة والسفر لكي تكون عملية تعيين العاملين عملية دقيقة وتؤدي إلى تعين الأفضل من بين المتقدمين لمارسة الوظيفة ،لابد أن

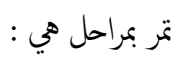
طلب التوظيف: حتى تقنتع المنشأة بالشخص المقدم اللوظيفة يجب أن يقدم إلهيا البيانات التي تؤيد ذلك ، وتفيد البيانات الواردة في التعرف على مقدرة الشخص على ترتيب أفكاره بوضوح، وتزود المنشاة بيانات أوليه عن
-

$$
\text { الخاصة بالشركة. }
$$

- - توفر أحد أنظمة الحجز الآلية في المكتب لرفع مستوى الخدمات

$$
\text { المقدمة. }
$$

O الوضع الإجتاعي والثقافي: تتحكم عادات الشعوب وتقاليدهم في جذب الآخرين لهم في أو دفع هؤلاء بعيداً عنه .و كرم الضيافة وحسن الإستقبال وطيب المعاملة هي الصفات التي تجذب السائح إلى البلد السياحي، وأيضا عناصر التراث الثقافي من أثثار تاريخية ومعالم أثرية كانت ولاتزال تمثل مقومات السياحة في العديد من البلدان. O الحراك الإجتاعي: يقصد به الفرص المتاحة لأفراد المجتع للتصرف في وقتهم وبما لديهم من حرية يقدون على إتخاذ قرارات متعلقة بعطلاتهم. O الأسعار: هي المقابل الذي يدفعه السياح نظير الخدمات التي تقدما

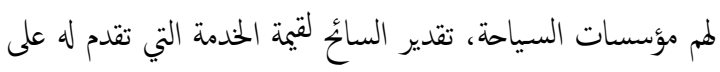
قياس منفعته من هذه الخدمة ،إذا كانت النكلفة ترهق ميزانيته فإنه يصرف النظر عن شرائها أو يحد من كيتها. O التنظيم الحكومي: تلعب النظم الحكومية والقوانين الحكومية دوراً محاً في تشجيع السياحة وتوسيع نطاقها أو العكس، فقوانين الجمارك والجوازات يككن أن تشكل عوائق حقيقية أمام المسافرين O الأداء الإعلاي: تمثل أبهزة الإعلام مرآه المجتمع وما يملكه من مقومات سياحية جاذبة وفرص سياحية تتيح للسائُ التمتع بوقته إلى أقصي درجة مككنة، فالدعاية باتت تمثل أهم أدوات الترويج السياحي.

3.3 ماهية المكاثب السياحية هي مكان يتم فيه القيام بالأعال المكتبية والفنية الخاصة بالنشاط السياحي سواء كان في داخل الدولة أو خاربها ، والمكتب السياحي قد يكون حكومياً يتبع لوزارة السياحة والهيئات الحكومية السياحية الأخرى، وقد يكون مكتبا يتبع لشركة سياحية أو وكلة سفر. الهدف من المكاتب السياحية ضان توفير خدمات مرضية لعملاء المكتب عن طريق تزويدها بالمعلومات المطلوبة وإنجاز ( مطالهم بسرعة وإتقان مما يدفعها إلى إستمرارية التعامل معه (عبدالله \&طاهر، 2013، 58. 


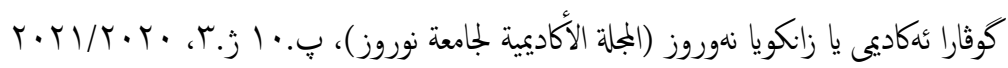

التعرف على مصادر حركة السياحة من السوق السياحي إلى الخارج سواء التقليدية أو غير التقليدية.
المتقدم .وتستخدم هذه البيانات كأساس لتوجيه الأسئلة اللازمة للحصول على المزيد من المعلومات والتي توجه الإختيار الشخصي(السعيدي،2009،

التعاون مع منظمي الرحلات الشاملة ووكلاء السياحة ومدهم بكل المواد الدعائية التي تساعدهم على جذب السائين مثل الكتيبات والإعلام وأشرطة الفيديو، وموافاة هذه الشركات بالمعلومات الخاصة بالتسهيلات السياحية وذلك بصفه مستمرة ويعتبر كمة رئيسيه ملكاتب السياحة الخارجية ، وعلى مدير المكتب محاولة إقناع منظمي رحلات ووكلاء سياحة وسفر جدد ضمن برامجهم السياحية الإشتراك في المعارض السياحية التي تقام في الدول الموجودة بها المكاتب وتنظيم ورش عمل وندوات للإشتراك مع كبري شركات الطيران ومنظمي الرحلات الشاملة وذلك لنعريف وكالات السياحة بالمقومات والتسهيلات السياحية المتوفرة(السعيدي،2009، 14)

إلقاء المحاضرات وعرض الأفلام على تجمعات من الجماهير المستهدفة في الجامعات أو الأندية الإجتاعية أو الندوات أو الإتحادات أو النقابات أو

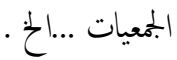
إعداد المواد الدعائية المطبوعة سواء الموبجة إلى السائين بوجه عام أو إلى السائين ذوي الإهتمات الخاصة. والرد على إستفسارات السائين الذين يزورون المكتب أو يتصلون به كتابة أو تلفونياً للحصول على معلومات عن

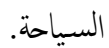

تحفيز حملات إعلان وعلاقات عامة في السوق كلما ظهرت الحاجة إلى ذلك بخلاف المملات التي ينفذها بجماز السياحة الرسمي. وإصدار نشرات إخبارية وصحفية في إطار النشاط الدعائي . الإيقاء على علاقات شخصية مع أهم الكتاب السياحيين ومدهم بالإخبار والصور عن السياحة ما يشجعهم على الكتابة عنها .

دعوة أهم وكلاء السياحة والكتاب السياحيين وغيرهم من رجال الإعلام

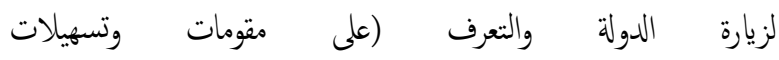
السياحة(عبدالله \&طاهر، 2013، 58). ومن أهم الخدمات التي تقدما وكالات السفر و السياحة الآتي:
السيرة الذاتية والتوصيات: تعتبر من أهم أجزاء السيرة الناتية معرفة التوصيات وتزكة الإدارات السابقة للشخص المتقدم ـ فن الحكمة والصواب أن يحصل المدير على كافة المعلومات التي تشير إلى علاقة الموظف مع إدارته السابقة، فهي تبين طبيعة تصرف الفرد في المؤسسات السابقة. الإختبارات: على جميع مكاتب السياحة والسفر إخضاع الموظف الجديد إلى إختبار لمعرفة قدراته ومهاراته. ويجب أن يشمل الإختبار إمكنية الموظف على القيام بهامه في حال وقع عليه الإختيار ، ويحتوي الإختبار على قدته على إستخدام الحاسوب وإصدار حجز التذاكر وغيرها من المهارات المتعلقة بجال السياحة والسفر.

الفحص الطبي: توجد عدد من مكاتب السياحة والسفر لا تطلب من المرشح للوظيفة فص طبي، بنيا تتطلب بعضها إجراء فص طبي للتأكد من عدم إدمان الشخص أو إصابته بأمراض معينه تعيقه من العمل بشكل صحيح. المقاباة الشخصية: تعتبر المقابلة الشخصية في غاية الأهية، فن خلالها يستطيع المرشح للعمل الحصول على معلومات حول ما ينظر من هذه الوظيفة، أيضا يستطيع المدير شرح ما تستطع أن توفره هذه الوظيفة. وهي وسيلة تترك لكلا الطرفين إتخاذ القرار بالموافقة أو الرفض (عدلي،2011، 37) - (37) التعيين: تعتمد عملية التعيين على قناعة المدير الشخصية وتقيمه لمستوى "ن المرشح معتماً على مقييس الأسئلة التي قدمت للمرشح والتي يمكن تؤمن طريق السلام في إتخاذ القرار الصواب. تثييت الموظفين وإعلاتم بمزايا الوظيفة: يجب أن تقوم الإدارة بتثبيت الموظفين الجدد في المواقع التي تتناسب مع خبراتهم ومهاراته. وتقديم نشرات خاصة توضح لم ما ينظر أن يقوموا به في الوظيفة (Zheng, 2010,190) دور الوكلات و المكاتب السياحية في التنشيط والترويج للسياحة تتمثل أهم أدوار مكاتب السياحة في تنشيط السياحة بالخارج في:- 
O يقوم بتنظيم البرامج المتكلمة من حيث الإقامة الفندقية والمزارات

$$
\text { الأثرية السياحية ووسائل الانتقال. }
$$

O الاتصال الفوري بوسائل النقل والفنادق وأماكن الزيارات لتنفيذ الخدمات.

O الرقابة المستمرة والتوجيه لمسئولي الحجز ومندوب الاستقبال والتوديع

$$
\text { مسؤول الحجز: يقوم بالواجبات الآتية: }
$$

O ممل جميع إجراءات الحجز للأفواج السياحية والسائين القادمين لما

O الحجز لدى الفنادق ووسائل الإقامة المختلفة.

$$
\text { O الحجز بالبواخر والمراكب العائمة. }
$$

O مجز الأتوبيسات والسيارات، حجز المرشدين السياحين.

$$
\text { O التأكد من تمام الحجز بصورة مستمرة. }
$$

O التنسيق المستمر مع معد البرامج ومندوب الاستقبال والتوديع

$$
\text { (السعيدي،2009، 14). (المئ) }
$$

عناصر البرنامج السياحي: يتكون البرنامج السياحي الذي تعده الشركة السياحية من عدد متنوع من الخدمات المختلفة حسب طبيعة كل برنامج هي. أولا : خدمة النقل(Transportation) : تتم هذه الخدمة بنقل السائ من الجهة المقيم فيها إلى بجة سياحية أخري أي من دولته إلى الدولة السياحية المقصودة تبعا لوسيلة السفر التي تنقسم إلى النقل الجوي أو النقل البحري

$$
\text { والنهري أو البري. }
$$

ثانيا: خدمة الإقامة(Accommodation): عنصر رئيسي من عناصر البرنامج السياحي ويتحدد مكان الإقامة بما يتفق مع نوعية المستهلكين السياحيين وإتجاهاتهم الخختلفة وتشمل الفنادق بأنواعها ومستوياتها المختلفة

$$
\text { والموتيلات والقرى السياحية والمخيات والشقق المفروشة. }
$$

ثالثا : خدمة الإعاثة(Meals) تتضمن البرامج السياحية خدمة الإعاشة

$$
\text { التي تشتمل على أربعة أنظمة من حيث عدد الوجبات اليومية ونوعيتها . }
$$

Meet Assist and ) رابعا: خدمة الإستقبال والانقالات والتوديع تشتمل على إستقبال السائين القادمين في الموانئ الجوية
الحجز: تقوم وكلات السياحة بحجز تذاكر طيران وبواخر، و ججز غرف

في فنادق محلية وعالمية بناء على طلب المستفيد.

تنظيم الرحلات السياحية الداخلية والخارجية من خلال برامج جذابة وبأسعار مغرية وتنافسية.

المرشد السياحي : من بين أدوار وكلات السياحية توفير مرشدين

$$
\text { سياحين للسياح المحليين أو الأجانب. }
$$

المتزجمين : تسعى وكلات السفر إلى توفير مترجمين للسياح الخارجين.

إستقطاب السياح : تقوم وكلات السياحة والأسفار بتقديم حملات دعاية

مدعمة ببرامج سفر جذابة وبأسعار منافسة لجذب أكبر عدد مككن من

الصفات الواجب توافرها في العاملين بشركات ووكالات السياحه والسفر (عوض

الله،2013، 19

المظهر اللائق فالمظهر يوحي بالثقة .

إجادة اللغات الأجنية وخاصة اللغة الانجليزية .

اللباقة وإجادة الحديث وقوة الإقناع ·

الصبر والتحمل في مختلف المواقف التي توابحها .

الحصول على شهادة أكاديمة مناسبة ويفضل أن تكون شهادة في تخصص

السياحة مع الخبرة(عبدالله\& طاهر، 2013، 40).

4.3

يتم الإعداد وتنظيم البرامج السياحية من خلال المكاتب السياحية داخل أقسام السياحة الموجودة بها فالمكتب السياحي يتشكل من بموعة عمل وهي المعدون

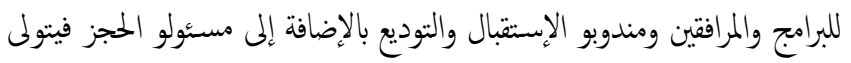
كل فرد منهم المسئوليات التي يحددها له المكتب السياحي (عدلي، 2011، 38.

$$
\text { معد البرنامج : يقوم بالمهام الآتية : م }
$$

O إرسال البرامج السياحية إلى الوكلاء السياحيين بالخارج ليبعها

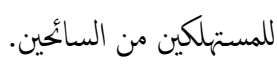

O يعمل على التنسيق مع المكاتب السياحية الختلفة في الخارج لتحديد أسعار البرامج السياحية. 


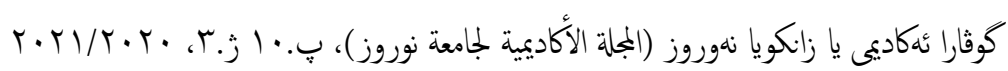

عدم توفير المواد الدعائية اللازمة-- خصوصا الكتيبات والأفلام- عن الأثماط السياحية الجديدة التي تحرص على طرحما وترويجها في بعض الأسواق الداخلية بهدف تنويع المنتج السياحي وفى مقدمتها سياحة

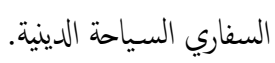
مازالت سياحة الآثار تمثل مركز الثقل بالنسبة لغاية الإعلانات التي تنشرها مكاتب هيئة تنشيط السياحية دون التركيز المناسب لإبراز التسهيلات والخدمات ووسائل اللهو والترفية المتوفرة والتي يبحث عنهاكل سائ عند اختياره لمنطقة الأجازة.

استراتيجية تطوير القطاع السياحي في العراق إن التطور الدائب الذي يطرأ علي التنية السياحة لابد أن يؤثر علي اتجاهاتها وأثماطها وهياكلها كصناعة، فالسياحة بدأت ترتبط بالترويح أكثر كثيرا من ذي قبل حتى أن عديد من خبراء السياحة أطلقوا علي هذه الفترة "عقد السياحة والترويء"، ويتسم هذا العقد بتغيرات عديدة مثل الاهتمام بالصحة العامة وزيادة آماد البشر والوعي البيئي والإيكولوجي، وتزايد اهتمام الناس بالحفاظ علي الصحة والتفكير في كل ما يقيدها والامتناع عن كل ما يضيرها، وتغير الاتجاه نو العمل والإنتاج بتزايد الاعتلد علي التكنولوجيا الحديثة والتقدم الملحوظ في تكنولوجيا المعلومات وارتفاع مستوي الرخاء الاقتصادي ومستوي نوعية الحياة في الدول، والزيادة المستمرة في أعداد المسافرين للسياحة وتعدد مقاصدهم ودوافعهم، وظهور أنماط جديدة كسياحة الاهثمات الخاصة والسياحة الايكولوجية وسياحة السفاري، كما اهتم بالتنمية السياحية العديد من الجهات في الدول المختلفة وعرفتها الجهات الحكومية على ان عملية التنمية السياحية تتمثل في تجهيز الاراضي المستهدفة للتنمية السياحية ( والتي تتوفر بها

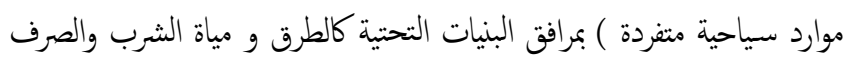
الصحي والكهرباء وتهذيب مسارات مخرات السيول بغرض المماية من أخطار السيول، وتزويد منطقة التنمية السياحية بخطوط الاتصالات اللازمة، وانشاء مجتعات عمرانية جديدة، وانشاء الخدمات الخختلفة في الصحة والثقافة والرياضة والتوويح والتجارة اللازمة للسائين والعاملين بقطاع السياحة في ننس

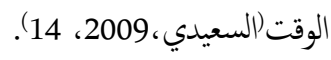
ومن المتفق علية أنة لاتوجد سياسة أو أستراتيجية صحية واحدة بعينها للنتمية السياحية يتعين أتباعها في مختلف الدول ولكن يتعين أختيار من بينها ما تتناسب مع الظروف الأقتصادية والأجتاعية والبيئية والثقافية الخاصة بالبلاد وبالمقصد
والبحرية والمنافذ البرية ونقاهم إلى الفندق الخحص لمم ويدخل في إطارها إجراءات نقل الأمتعة والجوازات والجمارك ..الح ، وأيضاً نقلهم إلى مكان المغادرة بواسطة الوسائل المخصصة لم وتوديعهم وعودتهم إلى أوطانهم . خامسا : خدمة المزارات (Sightseeing Service) تضم هذه الخدمة نقل السائين إلى الأمكاكن السياحية كناطق الآثار التاريخية والمتاحف والمعالم السياحية والحدائق..الخ وتشتمل على الإنتالات الداخلية وتسهيل زيارة المناطق السياحية والإرشاد السياحي ..اخ (عدلي،2011، 39. و ويرتبط البرنامج السياحي بخدمات أخري إلى عناصر البرنامج السياحي مثل

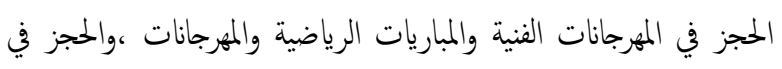
الحفلات الغنائية العالمية كالأوبرا وغيرها، والحجز في المعارض التاريخية والصناعية، وتأجير السيارات (يوسف كافي، 2016، 18). العقبات التي تواجه مكاتب ووكلات التنشيط السياح : تشير الدلائل إلى الحاجة الملحة لإدخال تطوير في الإستراتيجية الترويجية التي تنتجها مكاتب السياحة الرسمية لتنشيط السياحة ومن المهم أن نشير إلى أن دور مكانب التنشيط السياحي قد تتطور من مجرد كونها مراكز لبث المعلومات وتوزيع النشرات ومقابلة السائين ورجال الإعال إلى إن أصبحت هذه المكاتب بمثابة وحدات يقع على عاتقيها التعرف على كل المصادر المتاحة لحركة سياحية مرتقبة بالسنة للأنماط السياحية المتنوعة التي تتواجد داخل الدولة ثم العمل على إجراء اتصالات شخصية مع المسئولين في هذه المصادر لعرض وترويج المنتج السياحي. ومن أهم العقبات

$$
\text { التي تواجه تنشيط السياحة في الآتي: }
$$

عدم وجود استراتيجة ترويية شاملة تربط كل مكتب بأهداف محددة ويتمثل ذلك بشكل واضح فى غياب حملات إعلانية مدروسة تنبع من الإدارة المركزية ويتم تنفيذها بواسطة مكاتب هيئة تنشيط السياحة طبقا لرسالة إعلانية واضحة والمعالم مثلما هو متبع بالنسبة للدول السياحية المتقدمة. عدم كفاية الميزانيات الترويجية الخصصة للترويج الداخلي مما يقف عائقا رئيسيا أمام إمكانية تحقيق نتاجُج ذات قيمة. غياب عنصر التنسيق بالقدر المطلوب بين مكاتب السياحة و بعضها عن البعض مما لا يسمح للمسؤولين فيها بتبادل المعلومات والخبرة المكتسبة. 


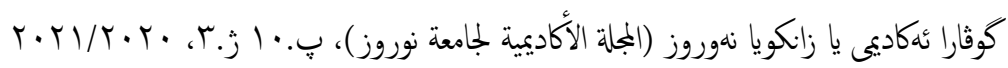

رفع معدل النمو الساحي في العراق من اجل دع المتغرات الأقتصادية نخو تحتيق النتية الوطنية الشاملة وخاصة زيادة الدخل السياحي زيادة تتناسب مع الزيادة المتوقعة لعدد الزوار الوافدين عن طريق تكرار الزيارت الساحية ورفع مستوى نوعية السائح وزيادة معدل أقامتة ومعدل أنفاقة اليوي وذلك يتطلب تنويع مكونات العراض السياحي وبالتالي تنويع الطلب السياحي من خلال دراسة السوق السياحية الرئيسية والثانويةو معرفة جنسيات وثقافة ودوافع الزوار القادمين الى العراق خاصة وأن البيانات تؤكد أختلاف وتنوع وبجات القدوم للزوار للسنوات الأخيرة وخاصة عام 2008 ويكن الأخذ بنظر الأعتبار الأجراءات والتسهيلات من ناحية دخول ومغادرة السياح والحصول على تأثيرة الدخول والتنظيم أجراءت التنيش الكمركي و غيرها، أضافة الم تطوير خدمات النقل الجوي والبري والنهري وصيانة البنى التحتية للمطارات الدولية ومحطات سكك الحديد بشكل خاص التي تعتبر وسيلة نقل أقتصادية كمة لأغلب الدول المتقدمة سياحيا. ب. التزكيز على السياحة الداخلية وتنظيها وتوفير مستلزمات تطورها لأهيا الركيزة الأساسية للسياحة الدولية وبالتالي ترفع من معنويات المواطن

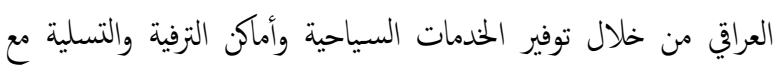
مراعاة الجودة والسعر المناسب والتقاليد والعادات والمفاهيم الدينية باختلاف بينتها الأجتاعية وفي جميع محافظات العراق. حاية الموارد التاريخية والأثرية والحضارية من التدهور والتلف وصيانتها المستمرة وحاية الموارد الطبيعية من التلوث نتيجة الحروب المستمرة والأسلحة المدمرة للتربة والهواء والبشر والحجر، من خلال التعاون والتنسيق بين وزارة السياحة وهيئة السياحة ودائرة الأثار والتزاث والأستعانة بمظظات دولية متخصصة في حاية الأثار والموروث التاريخي وهذا ما تؤكدة منظمة السياحة العالمية بالتعاون مع مؤتمر الأم المتحدة للتجارة والتنمية (UNCTAD) الى ترسيخ مبدأ أساسي السياحة هي توسي أحدى محركات التنمية المستديمة وحلية الأرث الطبيعي وأحدى الوسائل الكفيلة بمحاربة الفقر.وتأكيد حق الأجيال القادمة في التمع بالتراث الحضاري و الموارد الطبيعية التي هي أساس الجذب السياحي في العراق.
السياحي وبما ينلائم مع الطلب السياحي الداخلي والدولي المتاح والحتمل ولخمتلف

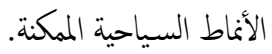
ولكي يتم أعادة هيكل القطاع السياحي العراقي من جديداً خذين بنظر الأعتبار المستجدات والتطورات في أدارة جديدة للنظام السياسي والأقتصادي العراقي وفي ظل النظام العالمي الراهن وحتى تضمن سياسة سياحية شاملة ومناسبة لأعادة الأرتباط مع السوق العالمية وبالشكل الأيجابي على الدولة وكافة الأجزة الرسمية وغير الرسمية ذات العلاقة كل حسب أختصاصة البدأ بالخطوات التالية وهي بمثابة اهداف ووسائل جديدة لصانعي القرار وواضعي السياسة السياحية وكالأتي

تغيير النظرة الجزئية الى القطاع السياحي الى نظرة شاملة مؤثرة وأن ترفع عن كاهله أغلال النعقيدات والروتين والقرارات الغير مدروسة بجيث يتحرر ويصبح مجالا خصباً لاثراء العراق والأسراع في تحقيق رخاء المواطنين

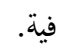
النظر في الأمكانيات المالية والأحتالية في سبيل تعبئنها بقصد تحقيق الأهداف المرسومةعلى أن تكون ليست نظرة أحادية البعد بل شاملة وهذا

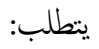
- - نظرة عينية ومالية لكافة الموارد المتاحة واللأزمة للتنمية السياحية الشاملة سواء موارد بشرية أو موارد سياحية ( مقومات الأنتاج السياحي) وموارد مالية التي تلزم لتعبئة الموارد المذكورة.

- نظرة تنظيمية تمكنا من تصور الأطار التنظيمي لتعبئة الموارد وتوليفها وذلك لأنة في غياب التنظيم الملائم تتبدد كل الموارد المتاحة.

تحديد الأهداف المتوخاة من السياسة السياحية لكي تكون مرشدا لهذة السياسة باتجاة طريق العمل السياحي السليم وأنة تتضمن الأهداف القومية أهدافا اقتصادية وأهدافا أجتاعية وسياسية وبيئية وفنية وثقافية ويككن أن تقسم أهداف قصيرة المدى ومتوسطة المدى وطويلة المدى حسب متطلبات التحولات للمرحلة الراهنة والمستقبلية وحسب قناعتنا يمكن تحديد الأهداف والوسائل المرسومة وحسب الأولوية كما يلي: 


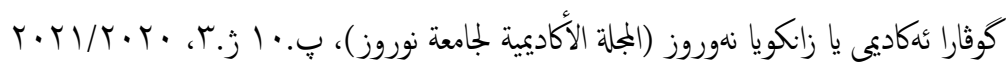

التربية ووزارة السياحة وهيئة السياحة ودائرة الأثار وزارة الصحة والبيئة

والأخحادات المهنة.

ويعتبر إقليم كردستان من المناطق السياحية الواعدة والوبجة السياحية المفضلة للسياح العراقيين طوال السنة حيث درجات الحرارة المنخفضة صيفاً وتساقط ردئ الثلوج شتاء. كما يعتبر الإقليم وبجة سياحية لسكان المناطق الحدودية من تركيا وايران التي يرتبط أهاليها بوشائج اجتاعية عديدة مع سكان الإقليم . وتتمتع المناطق الجبلية في الإقليم بمناظر خلابة ودرجات حرارة منخفضة صيفاً بالمقارنة بجميع المحافظات العراقية، كما تتميز بالشتوية حيث يجذب تساقط الثلوج السياح من جميع مناطق العراق إلى المناطق الجبلية.

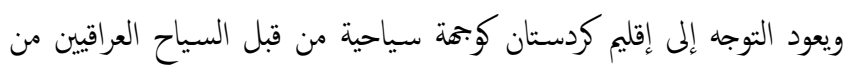

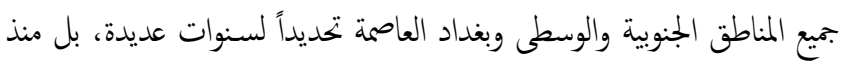
تأسيس الدولة العراقية في عشرينيات القرن الماضي؛ حيث ما زال القصر الملكي الصيفي لملوك العراق في القرن المنصرم شاخصاً للعيان في ناحية زاويتة في ضواحي مدينة دهوك (450كلم شمال بغداد)، وكذلك تسمية أربيل كماصمة صيفية للعراق

$$
\text { في سبعينيات القرن الماضي. }
$$

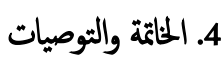

مما سبق يتضح أن للسياحة غايات من الممكن إدراكها بسهوة، فهي القطاع الأكثر جذبا للإستثارات الأجنية المباشرة، وهي القطاع الذي يمكن أن يسهم في تطوير القطاعات الأخرى. ولنا نزى أن السياحة في بعض الدول تحتل مكانة مرموقة من بين القطاعات الأخرى في الإقتصاد إنطلاقاً مما تدره من النقد الاجنبي. وفي الحتيقة إذا كما أريد أن تكون للسياحة مكانها اللائقة بها العراق عامة واقليم كردستان بطبيعتة الملابة خاصة، فإن الطريق المؤدية إليها لا تزال في بدايتها، ومع ذلك فالوصول إلى الهدف ليس مستحيلأ إذا تكثفت الجهود واستمرت. ومن هذا المنطلق نرى من الضروري تقديم بعض الضوابط الواجب تبنيها لإرساء ثقافة سياحية فعالة من خلال وكلات السياحة، منها: تسخير وسائل الإعلام للتعريف بالكنوز السياحية المتنوعة

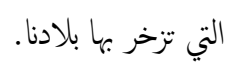

وضع إستراتيجيات سياحية ترنكز على المنطق وتنبثق من واقع العراق وتنفتح على الثقافات السياحية في العالم تأخذ

$$
\text { أحسنها وتتزك أسوأها. }
$$

د. ترك الحرية المنظمة للقطاع العام والخاص والمختلط ليؤدي كل منهم دورة في التنمية السياحية طبقا لضوابط التي يضعها التشريع مع تحديد سلطة الدولة في توجية عناصر صناعة السياحة والأشراف عليها لضانة سير العمل السياحي من خلال تحقيق استقرار البيئة الأقتصادية والسياسية بما تمتلكة من أدوات قيادية وتنفيذية وتشريعية ويكن أن يكون دورها مركزي ومساند في هذا الأطار حيث تحدد التوجيهات العامة للسياسة السياحية ثم تحدد بعض السياسات الدقيقة لدفع النشاط السياحي بأتجاة معين وعدم مزاحة القطاع الخاص في نشاطاتة مثلا (أقامة الجممعات والفنادق والمنتجعات والمطاعز والكازينوهات ووسائل الترفية والترويح الأخرى ـ الح) وأعطاء الدور للأتحادات والنقابات المهنية في رقابة أعحال القطاع الخاص الى تلى جانب الرقابة الحكومية ويبقى دور قطاع الأعال العام ( وزارة أو هيئة) في أطار التخطيط والتنظيم والتسويق والرقابة والتحفيزوهذة النقطة جديرة بالأهتام خاصة وأن النظام الأقتصادي القائم في العراق بعد 2003 لا يتصف بالأستقرار بأتجاة أقتصاد السوق أو التخطيط المركزي او النظام الخختلط ولكن من المهم المزاوجة بين التخطيط وألية السوق وضمان التكمل بين أدوات القطاعات العام والماص والخختلط في هذة المرحلة وما تفرضة من معطيات الوضع السياسي الحلالي وأتجاهاتة في عملية التحول والحرية وحسن الأختيار بين السياسات البديلة وبخطوات تدريية لكي نضمن أعادة الأرتباط بالسوق العالمية والأنفاح على العالم وحصول الثفاعل والتعاون وبناء المصاح في المجال السياحي. رفع مؤشرات تنمية القوى العاملة في القطاع السياحي من خلال السياسات المناسبة في الندريب والتعليم المهني المتخصص لضانة الكفاءة في الانتاج السياحي فيصبح الهدف المساهمة في تنمية وأستثمار القوى العاملة السياحية كما ونوعاً. اهداف تتعلق بسياسة البحوث والدراسات ومراكز الأستطلاع حول متطلبات المرحلة الحالية والمستجدات على الساحة المحلية والأقليمة والدولية لتجاوز المشاكل والأخرافات التي لا زالت تشكو منها الصناعة السياحية العراقية وكانت سبباً في نسيانها على الخارطة السياحية وبدون التنسيق والتعاون بين كل المهتين بالعمل السياحي من أكاديمين وخبراء في الجامعات والمعاهد المتخصصة في العراق مع وزارة التعليم العالي ووزارة 


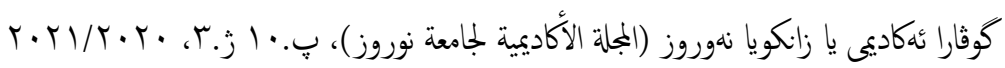

12. عادل عبد الله ، حميد الطاهر، التسويق في إدارة الضيافة، دار الزهري العلمية للنشر والتوزيج، 2013، ص48 ، 50

13. سعيد البطوطي، شركات السياحة ووكالات السفر، مكتبه الأنجلو المصرية، الطبعة

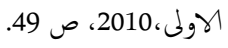

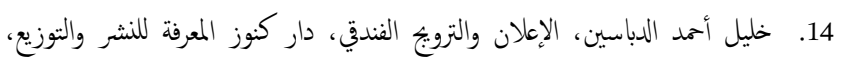

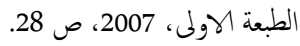
15. نشوي فؤاد ، تنميه المبيعات السياحية ، دار الوفاء لدنيا الطباعة والنشر، الطبعة الاولى، 2008، ص.69.

16. الطاهرمحد عوض الله ، وكالات السفر والسياحة تأسيسها إداراتها ونشاطها السياحي،

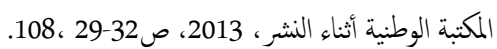

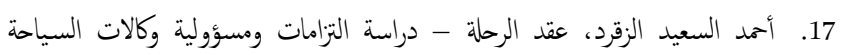

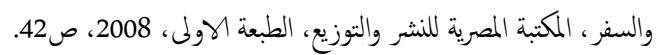

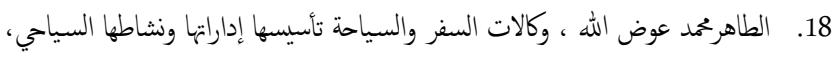
مرجع سابق، ص19.

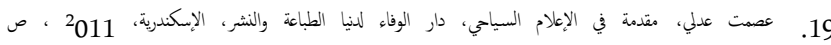
$.393^{35.37} ، 38$

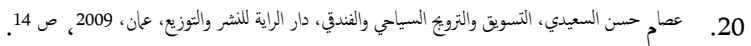

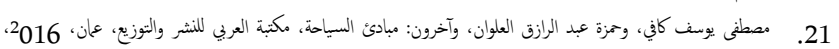

22. سعيد البطوطي، شركات السياحة ووكالات السفر، مكتبة الأنجلو المصرية، ط1،

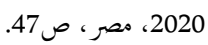

23. سامي عبد القادر سعيد، الإدارة الفندقية، بمحوعة النيل العربية، ط1، 2020، 2004،

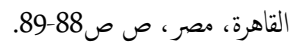

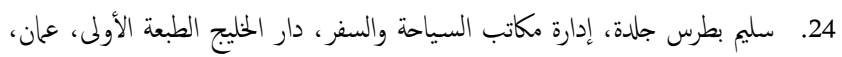

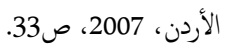
25. سليم بطرس جلدة، إدارة مكاتب السياحة والسفر، دار الخليج الطبعة الأولى، عمان، الان،

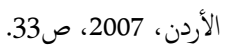
26. خالد مقابله، علاء السردادي، التسويق السياحي الحديث، دار وائل، ط13، 2001،

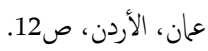
27. أحمد محمود مقابلة، صناعة السياحة، دار كنوز المعرفية العلمية، ط1، 2007، 2012، عمان،

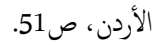
28. عبد القادر هدير، التسويق السياحي ودوره في ترقية الخدمات السياحية (دراسة حالة

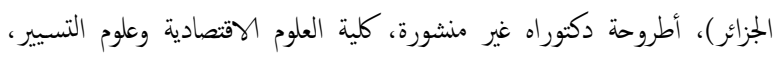

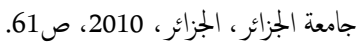

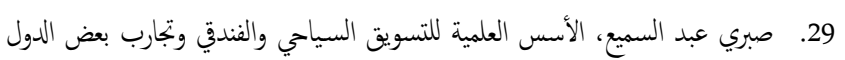

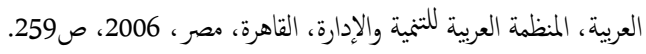

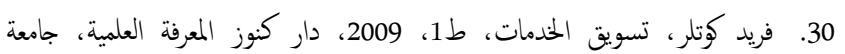
سكيكدة، الجزائر ، ص ص 282-283.

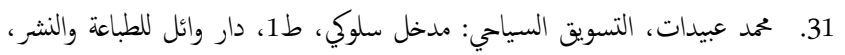

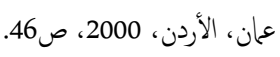
32. علي محمد ربابعة، بشير عباس العلاق، الترويج والإعلان التجاري: مدخل متكامل، دار

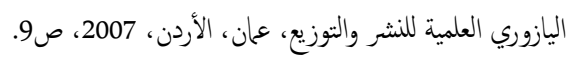

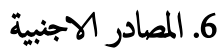

1. Burk at, A. j \& Medlik .Tourism -Past, Present \& Future, London. Second Edition ,pp $40 ، 41$
إنشاء معهد متخصص في السياحة وتدريب موظفي الوكالات السياحية تعمل على إرساء ثقافة سياحية لدى القائمين على المرافق السياحية المختلفة كل في موقعه ولدى المواطنين بواسطة الإشهار للتمكن من إستمرارية الجهود وتجسيد الاهداف بتكلة أقل وربح أكبر. صياغة نموذج لكل منطقة من المناطق السياحية، بجيث ينفرد كل نموذج عن الآخر بما يتلاءم وطبيعة كل منطقة وما تزخربه من إمكانات سياحية. إتقان اللغات الأجنبية الأكثر رواجا في العالم كاللغة الإنجليزية من طرف المرشدين لإمكانية التحاور والتفاهم وتجنب الحرج الذي قد ينجر عن إستعحال لغة لا يفهمها الساءُ. وجوب التحلي باللياقة الأدبية في التعامل مع السياح، محليين كانوا أم أجانب. ولا يككن أن يحدث ذلك إلا بالإختيار الدقيق لآشخاص إعتادا على معايير موضوعية. إعتماد الصدق في الكلمة والتفاني في العمل والحفاظ على الأمانة والرزانة في التعامل.

5. المصادر العربية

1. مروان السكر، مختارات من الاقتصاد السياحي، دار مجدلاوي للنشر والتوزيع،

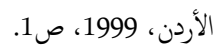

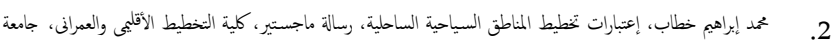

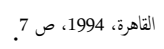
3. محود كامل، السياحة الحديثة علماً وتطبيقاً، القاهرة، الهيئة المصرية العامة للكناب، 1975، ص 11 4. خليل ابراهيم المشهداني، 1975، اثر التحضر في تطوير المواقع السياحية في مدينة كربلاء،

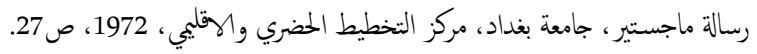

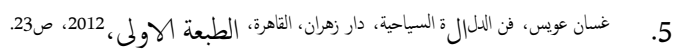
6. بشير العلاق، علي محمد رباعية، الترويج والإعلان التجاري، دار اليازوري، الأردن،

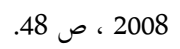
7. مصطفى عبد القادر، دور الإعلان في التسويق السياحي، دار مجد اللنشر و التوزيع، لبنان، 2005 ، ص ص م 3. 8. وليد سيد أمين، إدارة عميات شركات السياحة و وكالات السفر، دارآفق اللنشر

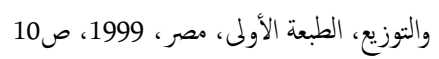

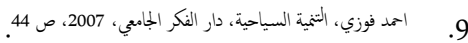

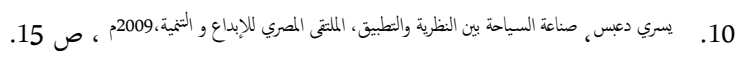
11. سعيد البطوطي، شركات السياحة ووكالات السفر، مكتبه الأنجلو المصرية، الطبعة صلم

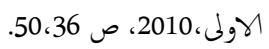




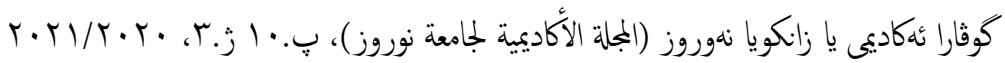

2. Chudhary, M. ( 2010). TOURISM MARKETING, First Edition, Oxford University Press, pp 56

3. Zheng, x. (2010) . role of social media in online travel information Search .tourisme management . 31 (2), pp 190.

4. Anthony,J.F and Seppo (1997),Annals of tourism Research, Vol14,Pergamon press, P.28. 